\title{
Telmisartan prevents development of obesity and normalizes hypothalamic lipid droplets
}

\author{
Elias Rawish1,2,3, Laura Nickel1,2,3, Franziska Schuster1,3, Ines Stölting1 , Alex Frydrychowicz', Kathrin Saar5,6, \\ Norbert Hübner5,6, Alaa Othman3,7, Lars Kuerschner ${ }^{8}$ and Walter Raasch1,2,3 \\ ${ }^{1}$ Institute of Experimental and Clinical Pharmacology and Toxicology, University of Lübeck, Lübeck, Germany \\ 2DZHK (German Centre for Cardiovascular Research), partner site Hamburg/Kiel/Lübeck, Lübeck, Germany \\ ${ }^{3}$ CBBM (Center of Brain, Behavior and Metabolism), Lübeck, Germany \\ 4Department of Radiology and Nuclear Medicine, University-Hospital Schleswig Holstein and University of Lübeck, Lübeck, Germany \\ 5 Max Delbruck Center for Molecular Medicine in the Helmholtz Association, Berlin-Buch, Germany \\ ${ }^{6}$ DZHK (German Centre for Cardiovascular Research), partner site Berlin, Berlin, Germany \\ 7Institute for Clinical Chemistry, University Hospital Zürich, Zurich, Switzerland \\ ${ }^{8}$ Life and Medical Sciences Institute (LIMES), University of Bonn, Bonn, Germany
}

Correspondence should be addressed to W Raasch: walter.raasch@uni-luebeck.de

\begin{abstract}
The $\mathrm{AT}_{1}$ receptor blocker telmisartan (TEL) prevents diet-induced obesity. Hypothalamic lipid metabolism is functionally important for energy homeostasis, as a surplus of lipids induces an inflammatory response in the hypothalamus, thus promoting the development of central leptin resistance. However, it is unclear as to whether TEL treatment affects the lipid status in the hypothalamus. C57BL/6N mice were fed with chow $\left(\mathrm{CON}_{\text {chow }}\right)$ or high-fat diet $\left(\mathrm{CON}_{\mathrm{HFD}}\right)$. HFD-fed mice were gavaged with TEL ( $8 \mathrm{mg} / \mathrm{kg} /$ day, 12 weeks, TEL $_{\mathrm{HFD}}$ ). Mice were phenotyped regarding weight gain, energy homeostasis, and glucose control. Hypothalamic lipid droplets were analyzed by fluorescence microscopy. Lipidomics were assessed by performing liquid chromatography-mass spectrometry in plasma and hypothalami. Adipokines were investigated using immunosorbent assays. Glial fibrillary acidic protein (GFAP) was determined by Western blotting and immunohistochemical imaging. We found that body weight, energy homeostasis, and glucose control of TEL-treated mice remained normal while $\mathrm{CON}_{\text {HFD }}$ became obese. Hypothalamic ceramide and triglyceride levels as well as alkyne oleate distribution were normalized in $\mathrm{TEL}_{\mathrm{HFD}}$. The lipid droplet signal in the tanycyte layer was higher in $\mathrm{CON}_{\mathrm{HFD}}$ than in $\mathrm{CON}_{\text {chow }}$ and returned to normal under $T_{E L_{H F D}}$ conditions. High hypothalamic levels of GFAP protein indicate astrogliosis of $\mathrm{CON}_{\text {HFD }}$ mice while normalized GFAP, TNF $\alpha$, and IL1 $\alpha$ levels of TEL $\mathrm{LFD}_{\text {HFD }}$ mice suggest that TEL prevents hypothalamic inflammation. In conclusion, TEL has anti-obese efficacy and prevented lipid accumulation and lipotoxicity, which is accompanied by an antiinflammatory effect in the murine hypothalamus. Our findings support the notion that a brain-related mechanism is involved in TEL-induced weight loss.
\end{abstract}




\section{Introduction}

Within the past few years, angiotensin II receptor (type 1) blockers (ARBs) have been shown to prevent the development of obesity in rodent models (He et al. 2010, Muller-Fielitz et al. 2012). Weight loss was observed both when telmisartan (TEL) was administered daily via the oral route to rats with fully diet-induced obesity in a treatment setting (Muller-Fielitz et al. 2014) and in patients during irbesartan therapy (Kintscher et al. 2007). These antiobese effects were only observed after giving high dosages of the drug and were found to be class effects and independent both of blood pressure reduction and of peroxisome proliferator-activated receptor gamma (PPAR $\gamma$ ) activation (Muller-Fielitz et al. 2011, 2012, 2014, Schuster et al. 2018).

Among other mechanisms, the antiobese effect of ARBs is dependent on intact leptin signaling. Leptin is a regulatory peptide, which is secreted by adipocytes as an afferent signal in a negative feedback loop, in order to induce anorexia after acting at its receptors in the brain (Friedman 2016). However, human obesity is not associated with an absence of leptin but rather with resistance to leptin activity (Konner \& Bruning 2012). We recently showed that (a) homozygous Zucker rats (which represent a genetic animal model for leptin resistance due to a onepoint mutation causing an amino acid substitution in the extracellular domain of the leptin receptor) remain obese despite ARB treatment, whereas heterozygous controls lose weight (Muller-Fielitz et al. 2011), (b) TEL treatment restores leptin sensitivity (Muller-Fielitz et al. 2015), and (c) TEL prevents diet-induced obesity and preserves leptin transport across the blood-brain barrier (BBB) in mice fed a high-fat diet (HFD) (Schuster et al. 2018). In addition to preventing obesity and restoring leptin sensitivity, TEL treatment normalized plasma levels of triglycerides (TGs), while TGs were markedly enhanced in control rats, which became obese and leptin resistant as a result of HFD feeding (Muller-Fielitz et al. 2014). This observation is in accordance with the notion of Banks, who asserted that high levels of circulating triglycerides have functional impact on the development of both peripheral and central leptin resistance and obesity by impairing leptin penetration through the BBB and leptin signaling in the brain (Banks et al. 2018).

In addition to peripheral alterations in TG concentrations, cerebral lipid levels have also been accused of altering food intake as prolonged intraventricular (i.c.v) infusion of mono-unsaturated oleic acid (OA) causes a decrease in food intake (Obici et al. 2002), whereas i.c.v infusion of saturated palmitic acid (PA) induces central leptin resistance, leading to an increase in food intake (Cheng et al. 2015). However, diminished total fatty acid levels were unexpectedly found in the hypothalami of rodents on a HFD despite having higher serum levels than lean controls (Le Foll et al. 2014). Using alkyne fatty acid tracers (Thiele et al. 2012) and click chemistry, which is based on a coppercatalyzed azide-alkyne cycloaddition to detect alkyne lipids (Kolb et al. 2001), Le Foll's finding was recently related to tanycytes, hypothalamic cells facing the third ventricle and playing a gatekeeper role in lipid processing (Hofmann et al. 2017). Thus, hypothalamic ketone body and neutral lipid synthesis as well as lipid droplets (LDs) in tanycytes are increased, possibly shielding unsaturated oleic acid from astrocytes (Hofmann et al. 2017). It was further discussed that tanycytes may act as a metabolic sink for surplus neutral lipids under obesity conditions where systemic fatty acids are abundant (Hofmann et al. 2017). In addition to lipid metabolism alterations under obesity conditions, tanycytes have functional importance in regulating metabolism for central leptin transport and further signaling in an extracellular signal-regulated kinase (ERK)-dependent manner (Balland et al. 2014) as well as for glucose sensing via an ATP-sensitive $\mathrm{K}$ channeldependent pathway (Frayling et al. 2011). Although the exact physiological mechanisms underlying glucoseinduced responses in tanycytes are not fully understood yet, studies indicate that lactate, as a metabolic substrate of glucose captured in tanycytes, is released by monocarboxylate transporters (MCTs) (Cortes-Campos et al. 2011). Lactate flux is suggested to be used by nearby neurons in the arcuate nucleus (ARC) to detect changes in glucose levels in order to regulate feeding behavior (Cortes-Campos et al. 2013). Accordingly, inhibiting MCT-1 or glucose transporter 2 (GLUT2) in tanycytes impairs the neuronal response to fasting and glucose administration accompanied by altered feeding behavior (Elizondo-Vega et al. 2016, Barahona et al. 2018). Hence, recent data emphasize that metabolic coupling between tanycytes, astrocytes, and neurons in hypothalamic areas is associated with regulation of feeding behavior.

Hypothalamic inflammatory processes have been shown to play a crucial role in the development of diet-induced obesity (Valdearcos et al. 2015). Although the exact cellular mechanisms remain incompletely understood, previous evidence suggests that the inflammatory response is mediated by interactions between neurons and glial cells such as astrocytes and tanycytes (de Git \& Adan 2015). Dietary fat increases the content of several lipids, such as saturated acyl-CoA 
species in the hypothalamus, activating the inhibitor of the kappa B kinase-beta (IKK $\beta$ ) pathway, which can induce central leptin and insulin resistance (Posey et al. 2009). Thus, hypothalamic lipotoxicity, based on an excessive accumulation of some lipid species causing metabolic alterations, is strongly assumed to be a key mechanism in the development of obesity (Gonzalez-Garcia et al. 2017).

Considering these findings, the aim of the present study was to investigate whether TEL treatment can normalize hypothalamic fatty acid metabolism and LD accumulation in the tanycyte region in mice despite HFD feeding while the amount of LD is high in obese but not in lean controls. We further asked whether TEL treatment can alter the hypothalamic lipidome of HFDfed mice, using mass spectrometry technique to focus on expected lipid accumulation and lipotoxicity due to HFD. Finally, we determined whether TEL treatment could normalize hypothalamic inflammation in HFDfed mice by measuring various inflammatory parameters via immunosorbent assays and microarray technique and determining glial fibrillary acidic protein (GFAP) via immunohistochemical and Western blot analyses. Indeed, astrogliosis in the hypothalamic region was identified to serve as a hallmark of CNS injury and lowgrade inflammation occurring in obesity in both rodents and humans, while it is largely reversible after becoming lean by returning to regular food (Jastroch et al. 2014). Thus, we show here that weight-reducing doses of TEL prevented lipid accumulation and lipotoxicity, which is accompanied by an anti-inflammatory effect in the murine hypothalamus.

\section{Materials and methods}

\section{Reagents}

Alkyne oleate was synthesized as described (Thiele et al. 2012). DAPI (4',6-diamidino-2-phenylindole) and general laboratory chemicals were obtained from Sigma-Aldrich. Lipid-free BSA was purchased from Applichem (Darmstadt, Germany). LD540 (4,4-difluoro-2.3,5.6-bis-tetramethylene4-bora-3a,4a-diaza-s-indacene) was synthesized as described previously (Spandl et al. 2009).

\section{Animals}

All animal care and experimental procedures were performed in accordance with the NIH guidelines for the care and use of laboratory animals and were approved by the animal ethics committee of the local regulatory authority (Ministerium für Energiewende, Landwirtschaft, Umwelt und ländliche Räume des Bundeslandes SchleswigHolstein). The results of all studies involving animals are reported in accordance with the ARRIVE guidelines. Male C57BL/6N mice (from Charles River Laboratories) aged 6-8 weeks were kept in individually ventilated cages in groups of two to five individuals at $23^{\circ} \mathrm{C}$ under a $12 \mathrm{~h} / 12 \mathrm{~h}$ dark (18:00 h-06:00 h)/light (06:00 h-18:00 h) cycle. All animals were habituated to laboratory conditions for at least 10 days before experiments were started. All animals had free access to water. A total of 99 mice were included in the two parts of the study (part 1: $n=39$, part 2: $n=60$ ). Functional studies and hypothalamic lipid analyses were mainly performed in part 1 , while gene expression was exclusively determined in part 2 .

\section{Study protocol (part 1)}

For the workflow of the first part of the study, see Supplementary Fig. 1 (see section on supplementary materials given at the end of the article). The group size was assessed by a power analysis (alpha value $=0.017$, power $80 \%$ ) to be at least $n=13$ in each group by expecting a weight difference of $8 \pm 6 \mathrm{~g}$ after TEL treatment. Two mice died of an unexpected anesthetic accident during MRI analyses. All animals were monitored daily by visual inspection and weighing. Mice received one of these two diets: HFD (EF acc. D12492 (I) mod. from ssniff ${ }^{\circledR}$, Soest, Germany) with $24.0 \mathrm{MJ} / \mathrm{kg}$ or normal fat diet (NFD, EF acc. D12450B mod. from ssniff $\AA$, Soest, Germany) with $18.0 \mathrm{MJ} / \mathrm{kg}$. Once a day, mice received TEL $\left(8 \mathrm{mg} / \mathrm{kg}_{\mathrm{bw}}\right)$ or vehicle by oral gavage in a volume of $5 \mu \mathrm{L} / \mathrm{g}$ body weight. TEL dosages were evaluated recently (MullerFielitz et al. 2012) and have been confirmed in numerous studies both in rats (Miesel et al. 2012, Muller-Fielitz et al. 2014, 2015, Schuchard et al. 2015, Winkler et al. 2016, Gustaityte et al. 2018) and in mice (Schuster et al. 2018, Dapper et al. 2019) to reveal antiobese effects. For administration, TEL was suspended in 10\% gum arabic (Carl Roth GmbH, Karlsruhe, Germany), resulting in a suspension of $1.6 \mathrm{mg} / \mathrm{mL}$ TEL. Mice were allocated by block randomization to the following groups: NFD and vehicle treatment $\left(\mathrm{CON}_{\text {chow }}\right)$, HFD and vehicle treatment $\left(\mathrm{CON}_{\mathrm{HFD}}\right)$, and HFD and TEL treatment $\left(\mathrm{TEL}_{\mathrm{HFD}}\right)$. Mice were phenotyped according to the following approach: at w6, energy expenditure (EE), respiratory exchange rate (RER), locomotion, and drinking and feeding behavior were determined in a subgroup of mice for 5 days by indirect calorimetry using the PhenoMaster SystemTM 
(TSE, Bad Homburg, Germany) (Schuster et al. 2018). Data were analyzed separately for light and dark periods (only considering a core period of $8 \mathrm{~h}$ for each period) and averaged for the 5 days. At w7, insulin sensitivity was determined by performing an insulin tolerance test (ITT) as recently described (Schuster et al. 2018, Dapper et al. 2019). To validate leptin sensitivity, a leptin resistance test (LRT) was performed at w8 (Dapper et al. 2019). Details of the ITT and LRT are specified in the Supplementary materials. At w10, fat mass was assessed by using MRI technique (Schuchard et al. 2015, Winkler et al. 2016). At w11, tail blood was withdrawn after a 6-h fasting period to determine plasma lipids. At w13, mice were killed, whereupon organs and blood were removed. As lipid droplet signal has already been demonstrated to be higher in tanycytes of obese than in lean mice by investigating only three animals each group (Hofmann et al. 2017), we performed hypothalamic lipid as well as immunosorbent and immunohistochemical analyses in a subset of five animals of each group here, as described below.

\section{Study protocol (part 2)}

For the workflow of the second part of the study, see Supplementary Fig. 2. In a second cohort of animals consisting of 60 mice (20 mice per group), we further aimed to investigate whether hypothalamic gene expression is altered in response to feeding and TEL. The group size was assessed by a power analysis (alpha value $=0.008$, power $80 \%$ ) to be at least $n=20$ in each group by expecting genetic differences of $15 \pm 12 \%$ of hypothalamic (an)orexigenic peptides (Muller-Fielitz et al. 2014, 2015, Schuchard et al. 2015). Feeding and treatment were analogous to the aforementioned approach without performing any functional characterization, except for body weight. After 6 weeks, animals were killed and hypothalami were removed for microarray analysis following tissue homogenization by using a Bullet Blender ${ }^{\circledR}$ and the Bullet Blender® PINK Bead Lysis Kit (both Next Advance, Troy, USA) and then isolating RNA by using the NucleoSpin ${ }^{\circledR}$ RNA Kit (Macherey-Nagel, Düren, Germany) according to the manufacturer's instructions. The RNA was processed and hybridized on the Affymetrix Mouse Gene 2.0 Array (Thermo Fisher Scientific) according to the manufacturer's protocol (Schuster et al. 2018).

\section{Preparation of brain slices}

For lipid analysis, brain slices (bregma level -1.4 to -1.9 , $250 \mu \mathrm{m}$ thickness, vibratome) were prepared immediately following decapitation and incubated with $50 \mathrm{mM}$ alkyne oleate according to a previously described protocol (Hofmann et al. 2017); for detailed information, see Supplementary materials. For immunohistochemistry, mice were transcardially perfused with $25 \mathrm{~mL}$ of PBS and then with $25 \mathrm{~mL}$ of $4 \%$ paraformaldehyde (PFA) in PBS at a flow rate of $20 \mathrm{~mL} / \mathrm{min}$. Slices (bregma level -1.7 to $-1.8,50 \mu \mathrm{m}$ thickness, vibratome) were fixed, adding $4 \%$ PFA to the PBS for 10 min before washing with PBS.

\section{Hypothalamic lipid analyses}

Hypothalamic LDs containing neutral lipids were (semi-) quantified in brain slices by staining LDs with LD540, a lipophilic dye developed for imaging of lipid droplets (Spandl et al. 2009), and the micrographs were then quantified (see below). Hypothalamic neutral glycerolipids as well as phosphoglycero-, sphingo-, and acylcarnitine lipids were analyzed by liquid chromatography-mass spectrometry (LC-MS, see Supplementary materials). Hypothalamic fatty acid metabolism was analyzed in the slices using tracer alkyne oleate and detection by copper(I)-catalyzed azide-alkyne cycloaddition, CuAAC, commonly termed click chemistry (Hofmann et al. 2017). This method combines high sensitivity with fast sample turnover and is free of radioactivity (Thiele et al. 2012). Alkyne oleate was localized by fluorescence microscopy using a biotinylated azide reporter (SigmaAldrich, product no. 762024) and streptavidine-Alexa 488 conjugate (BioLegend, San Diego, USA) as described previously (Hofmann et al. 2014). Cellular alkyne oleate metabolites were characterized by reacting hypothalamic lipid extracts with 3-azido-7-hydroxycoumarin (Baseclick, Neuried, Germany, product no. BCFA-047) before performing thin-layer chromatography (TLC) as described previously (Thiele et al. 2012).

\section{Microscopy}

Epifluorescence microscopy was performed using a Zeiss Observer. Z1 microscope (Carl Zeiss) equipped with a Fluar 40x (1.30 NA) objective and a Photometrics Coolsnap K4 camera (Teledyne Photometrics, Tucson, USA). Optical sectioning was performed using the apotome mode, which also served to avoid stray light due to slice thickness. The light source was a Polychrome V $150 \mathrm{~W}$ Xe lamp (Till Photonics, Graefeling, Germany). All images were processed by employing the ZEN (Carl Zeiss) and Fiji (Schindelin et al. 2012) software. If appropriate, projections of z-stacks were calculated by summarizing corresponding 
pixel values using Fiji software. For semi-quantitative analysis of immunostaining, all corresponding samples were processed identically in the same dish on the same day (details in Supplementary materials). Samples for lipid analysis were processed identically on different days. Identical acquisition settings were applied to record all corresponding images. Blinded semi-quantification was performed using Fiji software according to modified, previously described procedures (Hofmann et al. 2017).

\section{Biochemical analysis}

Blood glucose was measured using a commercial glucose sensor (Ascensia Elite XL and Elite Sensor, Bayer Vital $\mathrm{GmbH}$, Leverkusen, Germany). Plasma concentrations of diverse adipocytokines were measured in $10 \mu \mathrm{L}$ of sample by immunosorbent assays according to the manufacturer's instructions using the Milliplex mouse metabolic magnetic bead panel kit MADKMAG-71K-07.mouse (interleukin-6 (IL6), insulin, leptin, MCP1 (monocyte chemoattractant protein-1), PAI1 (plasminogen activator inhibitor 1), resistin, TNF $\alpha$ (tumor necrosis factor- $\alpha$ )) and MHSTCMAG70K-13 mouse high-sensitivity equipment (granulocytemacrophage colony-stimulating factor (GM-CSF), interferon gamma (INFy), IL10, IL12, IL13, IL1a, IL2, IL4, IL5, IL7, IL6, MCP1, and TNF $\alpha$; all from Merck/Millipore). We also determined adipocytokines in the hypothalamic tissue samples. Thus, slices of hypothalami (bregma level -1.4 to $-1.9,250 \mu \mathrm{m}$ thickness, vibratome) were homogenized in $120 \mu \mathrm{L}$ phosphate buffer (containing $0.2 \%$ Triton $\mathrm{X}-100)$. Then, $5 \mu \mathrm{L}$ of this homogenate were used for protein analysis for normalization according to the Bradford method (Sigma-Aldrich) and $10 \mu \mathrm{L}$ of tissue homogenate were mixed with $10 \mu \mathrm{L}$ saline and centrifuged $(10 \mathrm{~min}, 1000 \mathrm{~g})$. Following this, $10 \mu \mathrm{L}$ of supernatant was used for immunosorbent assays. The lipid profiles in plasma and hypothalami were analyzed according to other published methods (Othman et al. 2012) with slight modifications (for detailed information, see Supplementary materials).

\section{GFAP immunohistochemistry (IHC)}

For IHC analyses, fixed slices (see above) were transferred to 24-well culture plates containing PBS. Blocking buffer (1\% BSA, $0.1 \%$ Triton X-100 in PBS) was added for $1 \mathrm{~h}$ before incubation with primary antibody GFAP (Synaptic systems, Göttingen, Germany, product no. 173004, 1:500) in blocking buffer at $4^{\circ} \mathrm{C}$ overnight. PBS was used for washing, incubation with secondary antibody (goat anti-guinea pig A488, Invitrogen, Thermo Fisher Scientific, product no. A-11073, 1:500), and DAPI (1:100) staining before mounting.

\section{Western blot analysis of GFAP}

Equal amounts of proteins (50 $\mu \mathrm{g}$ in $40 \mu \mathrm{L})$ were separated on $7.5 \%$ SDS-polyacrylamide gels. Equal loading was confirmed by incubating the membranes with actin mouse antibodies (Merck-Milipore, product no. MAB 1501, 1:5000). Target proteins were detected by applying a guinea pig antibody specific for GFAP (Synaptic Systems, Göttingen, Germany, product no. 173004, 1:2500). Immunocomplexes were then labeled with the corresponding horseradish peroxidase-conjugated anti-mouse or anti-guinea pig IgGs (Dako) and semiquantitatively detected by enhanced chemiluminescence (West Dura substrate, Fisher Scientific) using a highresolution CCD (charge-coupled device) camera (ChemiDoc system and Quantity One software, Bio-Rad).

\section{Calculations and statistics}

Data and statistical analysis comply with the recommendations for experimental design and analysis in pharmacology. In graphs and tables, data are expressed as means \pm S.D. Food intake was determined by the Phenomaster System and consumed energy was calculated using the energy density of the special diets $(24 \mathrm{~kJ} / \mathrm{g}$ and $18 \mathrm{~kJ} / \mathrm{g}$ ). In order to quantify the total effect over the observation period in response to ITT, areas under the curves (AUCs) were calculated for each individual animal based on their plasma glucose delta values. $\mathrm{C}_{\min }$ values were also calculated considering delta values. All data were checked for outliers using the GraphPad® outlier calculator (http://graphpad.com) and tested for Gaussian distribution and variance homogeneity (GraphPad Prism 8). Strain differences were evaluated by 2-way ANOVA, followed by Bonferroni's multiple comparison post-test to prove treatment effects. A two-way or one-way ANOVA was only performed when Gaussian distribution and variance homogeneity were detected. Bonferroni's multiple comparison post hoc test was only performed if $P$ was $<0.05$. Welch's correction for ANOVA was considered when variance inhomogeneity between groups was detected. Kruskal-Wallis test with Dunn's multiple comparison test was used when values were not distributed in a Gaussian fashion. Correlation analyses were performed https://joe.bioscientifica.com https://doi.org/10.1530/JOE-19-0319 (c) 2020 Society for Endocrinology Published by Bioscientifica Ltd. 
by two-tailed Pearson test. Signals gained from microarray experiments were normalized by Affymetrix Expression Console Software and both log values and fold-changes were calculated. These data were statistically examined by Affymetrix Transcriptome Analysis Console Software (Thermo Fisher Scientific).

\section{Results}

\section{Effects on growth, energy homeostasis, and plasma levels of lipids and adipocytokines}

Initial body weight did not differ between groups $\left(\mathrm{CON}_{\text {chow }}\right.$ $23.3 \pm 1.4 \mathrm{~g} ; \mathrm{CON}_{\mathrm{HFD}} 22.8 \pm 1.4 \mathrm{~g} ; \mathrm{TEL}_{\mathrm{HFD}} 23.2 \pm 1.8 \mathrm{~g} ; \mathrm{F}=0.4$, $P=0.68)$. HFD-fed mice developed obesity as both final body weight and fat mass clearly exceeded those of chowfed controls. TEL treatment normalized weight gain and fat mass despite HFD feeding (Fig. 1A and B). Accordingly, organ weights were enhanced when mice were fed with HFD but remained at or even below chow levels when simultaneously treated with TEL (Fig. 1C, D and E). Similar findings on body weight in response to HFD feeding and TEL treatment were also observed in the 2 nd group of mice, which was used for microarray analyses of inflammation parameters (Supplementary Fig. 3).

The increase in both plasma leptin and body weight already suggested that leptin resistance had developed in HFD-fed mice (Fig. $1 \mathrm{~F}$ and $\mathrm{H}$ ). The findings that hypothalamic leptin content was almost undetectable (Fig. $1 \mathrm{G}$ and $\mathrm{H}$ ) in HFD-fed mice and that body weight in LRT was not reduced compared to chow-fed controls (Fig. 1I) further indicate that HFD-fed controls developed leptin resistance. In contrast, plasma leptin, hypothalamic leptin content, and body weight gain upon leptin challenge stayed at normal chow levels as a result of TEL treatment despite HFD feeding (Fig. 1F, $\mathrm{G}, \mathrm{H}$ and I). Following immunosorbent analyses, the plasma concentration of PAI1 was higher in $\mathrm{CON}_{\mathrm{HFD}}$ than in $\mathrm{CON}_{\text {chow }}$, but normalized in $\mathrm{TEL}_{\mathrm{HFD}}$ mice, while the levels of IL4 and IL6 were higher in both $\mathrm{CON}_{\mathrm{HFD}}$ and $\mathrm{TEL}_{\mathrm{HFD}}$ mice. IL5 levels were higher in $\mathrm{TEL}_{\mathrm{HFD}}$ than in $\mathrm{CON}_{\text {chow }}$ mice. IL13 was similar in all groups (Table 1). IL1 $\alpha$ and IL10 were below the detection limit in most samples of all groups. Lipids in plasma were determined by LC-MS. In particular, ceramides, cholesteryl esters, phosphatidylcholines, phosphatidylethanolamines, and sphingomyelins were higher in both $\mathrm{CON}_{\mathrm{HFD}}$ and TEL $\mathrm{H}_{\mathrm{HFD}}$ mice, with the exception that ceramides were normalized to chow levels by TEL (Table 2 and Supplementary Fig. 4).
Obesity of HFD-fed mice was related more to lower energy expenditure and locomotion (Fig. 2A and E) than to a heightened energy intake, which was, at least in the dark phase, even slightly reduced (Fig. 2C). Upon TEL, energy expenditure was higher, whereas energy intake was lower than in HFD-fed controls in the dark periods (Fig. 2A and C). Due to high-fat feeding, RER varied in HFD controls and TEL-treated mice between 0.75 and 0.8 , thus indicating fat metabolization, while RER was almost 1.0 in chow-fed controls, prompting utilization of carbohydrates (Fig. 2B). Water intake was reduced by HFD feeding but increased above chow levels as a result of TEL treatment (Fig. 2D).

\section{Effects on glucose homeostasis}

While plasma glucose was higher in $\mathrm{CON}_{\mathrm{HFD}}$ and $\mathrm{TEL} \mathrm{L}_{\mathrm{HFD}}$ than in $\mathrm{CON}_{\text {chow }}$ mice, TEL normalized plasma insulin, suggesting that insulin sensitivity was not impaired as much as in $\mathrm{CON}_{\mathrm{HFD}}$ mice (Fig. $3 \mathrm{~A}$ and $\mathrm{B}$ ). This conclusion is supported by the observation that glucose utilization was better in $\mathrm{TEL}_{\mathrm{HFD}}$ than in $\mathrm{CON}_{\mathrm{HFD}}$ as the AUC and the $\mathrm{C}_{\min }$ levels in response to the ITT were higher (Fig. 3C, D and E).

\section{Effects on hypothalamic lipids}

The signal of the neutral lipid containing LD was quantified by epifluorescence microscopy as exemplarily illustrated in Fig. 4A. The LD signal in tanycytes was ten-fold higher in $\mathrm{CON}_{\mathrm{HFD}}$ than in $\mathrm{CON}_{\text {chow }}$ and declined to normal in TEL $_{\text {HFD }}$ mice (Fig. 4B). Hypothalamic levels of the neutral lipids, triglycerides, and ceramides (Cer) (particularly TG(56:5), TG(56:6), TG(56:7), TG(58:8) and Cer(d36:1) (d18:1/18:0)) were higher in $\mathrm{CON}_{\mathrm{HFD}}$ than in $\mathrm{CON}_{\text {chow }}$ and normalized in $\mathrm{TEL}_{\mathrm{HFD}}$ mice (Fig. 4C). Hypothalamic content of other lipids, including free fatty acids, did not differ between groups with the highest levels of phosphatidylcholine and phosphatitylethanolamine and the lowest levels of diacylglycerol (Supplementary Figs 5 and 6). Analysis of hypothalamic acute lipid metabolism in brain slices showed a lower signal of alkyne oleate-derived lipids in the ARC of $\mathrm{CON}_{\mathrm{HFD}}$ than in $\mathrm{CON}_{\text {chow }}$ mice, while no difference was observed in the tanycyte layer. TEL again normalized alkyne oleate signal distribution (Fig. $5 \mathrm{~A}$ and $\mathrm{B}$ ). Despite these changes in intrahypothalamic alkyne lipid localization, no alterations in the metabolic fate of the alkyne oleate tracer was observed between the groups (Fig. 5C). 

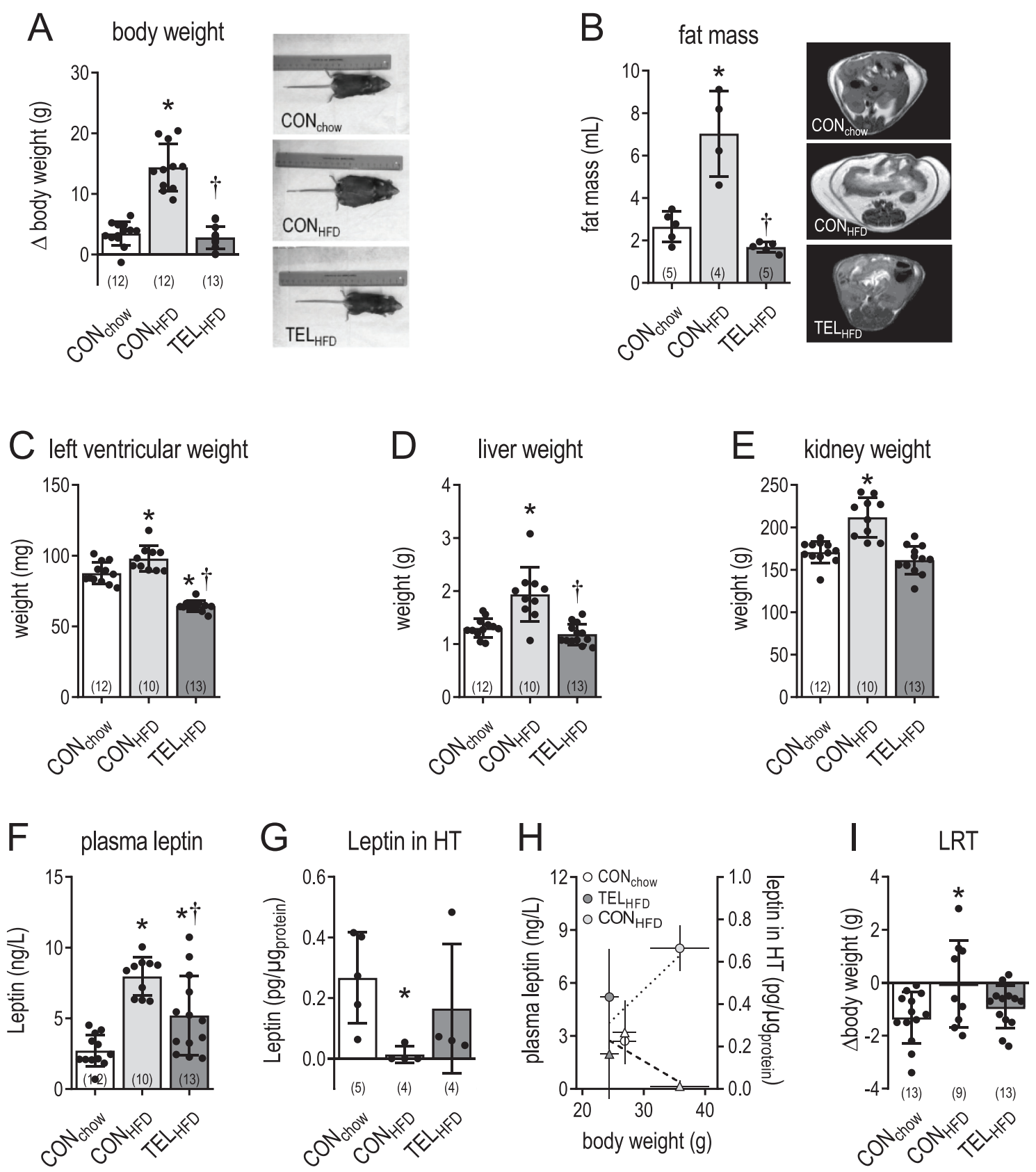

Figure 1

Growth of mice upon chow ( $\mathrm{CON}_{\text {chow }}$ ) or HFD feeding plus vehicle treatment ( $\mathrm{CON}_{\mathrm{HFD}}$ ) and HFD feeding plus TEL treatment (TEL $\left.\mathrm{HFD}_{\mathrm{H}} 8 \mathrm{mg} / \mathrm{kg} / \mathrm{day}\right)$. (A) Gain in body weight ( $F W=63.0, P<0.0001)$; (B) Fat mass ( $F W=15.5, P=0.0071)$, (C) Left ventricular weight $(F=89.3, P<0.0001)$, (D) Liver weight ( $F W=9.3$, $P=0.0017)$, (E) Kidney weight ( $\mathrm{F}=24.9, P<0.0001)$. ( $\mathrm{F})$ Plasma leptin ( $\mathrm{F}=49.1, P<0.0001)$; (G) Leptin content in hypothalamus $(\mathrm{FW}=6.8, P=0.041) ;(\mathrm{H})$ Correlation between final body weight and leptin levels in plasma (left $\mathrm{Y}$-axis, dots, $r=0.763, r=0.447$ ) or hypothalamus (right $\mathrm{Y}$-axis, triangles; $r=-0.814$, $P=0.394) ;(I) C h a n g e$ in body weight after 4 days in leptin resistance test (LRT, $\left.F^{W}=3.3, P=0.05\right)$. Means \pm s.D.; Statistical differences between groups were calculated by ANOVA followed by Bonferroni's multiple comparison test or Welsh ANOVA test (indicated by FW) followed by Games-Howell's multiple comparisons test in case of variance inhomogeneity. ${ }^{*} P<0.05$ vs $\operatorname{CON}_{\text {chow }}{ }^{i} P<0.05$ vs $\operatorname{CON}_{\text {HFD }}$.

\section{Effects on hypothalamic inflammation}

GFAP immunofluorescence signal was three times higher in the $\mathrm{ARC}$ of $\mathrm{CON}_{\mathrm{HFD}}$ than in $\mathrm{CON}_{\text {chow }}$ mice but returned to normal levels when HFD-fed mice were simultaneously treated with TEL. Moreover, the GFAP signal positively correlated with body weight (Fig. 6A). Western blot analysis confirmed the immunohistochemical results (Fig. 6B). Using immunosorbent assays, hypothalamic cytokine levels were quantified in a small subgroup of 
Table 1 Adipokines in plasma of mice upon chow ( $\left.\mathrm{CON}_{\text {chow }}\right)$ or HFD feeding plus vehicle treatment (CON $\left.\mathrm{HFD}_{\text {f }}\right)$ and HFD feeding plus TEL treatment ( $\mathrm{TEL}_{\mathrm{HFD}}, 8 \mathrm{mg} / \mathrm{kg} /$ day).

\begin{tabular}{lcc}
\hline Plasma adipokine & & CON $_{\text {chow }}$ \\
\cline { 1 - 1 } Resistin (ng/L) & & $1.50 \pm 0.29(12)$ \\
Pai1 (ng/L) & & $1.13 \pm 0.32(12)$ \\
II4 (ng/L) & $0.31 \pm 0.57(11)$ \\
II5 (ng/L) & $19.5 \pm 22.4(11)$ \\
II6 (ng/L) & n.d. (11) \\
II3 (ng/L) & $39.2 \pm 10.9(9)$ \\
\hline
\end{tabular}

\begin{tabular}{c}
\hline CON $_{\text {HFD }}$ \\
\hline $2.9 \pm 0.91(10)^{\mathrm{a}}$ \\
$1.89 \pm 0.25(10)^{\mathrm{a}}$ \\
$2.87 \pm 2.7(9)^{\mathrm{a}}$ \\
$39.91 \pm 28.69(9)$ \\
$22.6 \pm 26.2(9)$ \\
$63.5 \pm 39.5(9)$ \\
\hline
\end{tabular}

\begin{tabular}{c}
\hline TEL $_{\text {HFD }}$ \\
\hline $2.69 \pm 0.85(13)^{\mathrm{a}}$ \\
$1.13 \pm 0.18(13)^{\mathrm{b}}$ \\
$3.02 \pm 3.13(10)^{\mathrm{a}}$ \\
$74.6 \pm 74.1(11)^{\mathrm{a}}$ \\
$24.7 \pm 40.5(11)$ \\
$43.1 \pm 14.5(8)$
\end{tabular}

$\begin{aligned} & \\ F W & =19.9, P<0.0001 \\ F W & =3.9, P=0.038 \\ H & =8.4, P=0.015 \\ H & =6.9, P=0.038 \\ H & =8.3, P=0.016 \\ F & =2.2, P=0.331\end{aligned}$

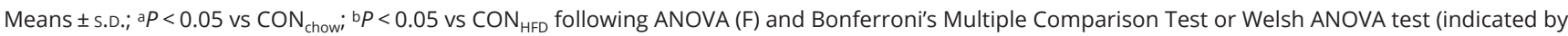
FW) followed by Games-Howell's multiple comparisons test or Kruskal-Wallis test (indicated by $\mathrm{H}$ ) and Dunn's multiple comparisons test. The number sizes are enclose in brackets. IL-6 levels were not detectable (n.d.) in $\mathrm{CON}_{\text {chow. }}$

each treatment group. Following ANOVA analysis, TNF $\alpha$ was found to be slightly higher in HFD- than in chowfed mice. This trend was also observed for IL1 $\alpha$ and IL13. However, it should be considered that the number of samples here is critically low for reliable, robust findings (Fig. 6C). Using the gene array technique, we analyzed hypothalamic expression of 34,471 genes and found that expression levels of 1736 hypothalamic genes differed between $\mathrm{CON}_{\text {chow }}$ and $\mathrm{CON}_{\mathrm{HFD}}$ mice, while 301 of these 1736 genes were again normalized by TEL. While gene expression of GFAP, Il1a, Il6, Il13, and TNF was not influenced either by HFD feeding or by TEL treatment, expression levels of neurotrophin 5 and cytochrome c oxidase subunit 5B (mitochondrial) were reduced in $\mathrm{CON}_{\mathrm{HFD}}$ and those of neurotrophin 5 were normalized in $\mathrm{TEL}_{\mathrm{HFD}}$ mice (Table 3). In contrast, expression levels of peroxiredoxin 3, SerpinA3N, Cxcl12 (C-X-C motif chemokine 12), and follistatin-like 1 were higher in $\mathrm{CON}_{\mathrm{HFD}}$ and again normalized in $\mathrm{TEL}_{\mathrm{HFD}}$ mice (Table 3 ). Expression of components of the renin angiotensin II system (RAS) was similar between different groups with the exception that expression of ACE was higher in $\mathrm{CON}_{\text {chow }}$ and $\mathrm{CON}_{\mathrm{HFD}}$ than in $\mathrm{TEL}_{\mathrm{HFD}}$ and that of $\mathrm{AT}_{2}$ receptor was lower in $\mathrm{CON}_{\mathrm{HFD}}$ than in $\mathrm{TEL}_{\mathrm{HFD}}$ (Supplementary Fig. 7).

\section{Discussion}

Confirming our previous findings (Muller-Fielitz et al. 2012, 2014, 2015, Schuchard et al. 2015, Winkler et al. 2016, Schuster et al. 2018), chronic TEL treatment of HFD-fed mice attenuated an increase in body weight, decreased food intake, and normalized leptin sensitivity, locomotion, energy expenditure, and glucose utilization to $\mathrm{CON}_{\text {chow }}$ levels in the current study as well.

As the aim of inhibiting $\mathrm{AT}_{1}$ receptors is not primarily to regulate food intake, the question arises as to why chronic ARB treatment has this efficacy. Based on our previous work, we assume that, in particular, CNS-dependent mechanisms may be involved as TEL markedly reduced weight gain and energy intake in rodents fed with HFD but only to a minor extent in transgenic rodents with a brain-specific deficiency in angiotensinogen (Winkler et al. 2016). Confirming the notion of an underlying central mechanism, the hypothalamic expression of the orexigenic neuropeptide $\mathrm{MCH}$ (melanin-concentrating hormone) was diminished in lean controls but not in obese Zucker rats in response to chronic ARB treatment (Muller-Fielitz et al. 2011). In this context, the expression levels of neurotrophin 5 ,

Table 2 Lipids in plasma of mice upon chow $\left(\mathrm{CON}_{\text {chow }}\right)$ or HFD feeding plus vehicle treatment (CON $\left.\mathrm{HFD}\right)$ and HFD feeding plus TEL treatment ( $\mathrm{TEL}_{\mathrm{HFD}}, 8 \mathrm{mg} / \mathrm{kg} /$ day).

\begin{tabular}{l}
\hline Lipid $(\mu \mathrm{M})$ \\
\hline Ceramide \\
Cholesterol ester \\
Lysophosphatidyl ethanolamine \\
Lysophosphatidylglycerol \\
Phosphatidylcholine \\
Phosphatidylethanolamine \\
Sphingomyelin \\
Triglyceride
\end{tabular}

\begin{tabular}{c}
\hline CON $_{\text {chow }}(n=13)$ \\
\hline $0.72 \pm 0.16$ \\
$4020 \pm 611$ \\
$20.8 \pm 5.3$ \\
$0.56 \pm 0.34$ \\
$457 \pm 57$ \\
$8.9 \pm 2.6$ \\
$82.6 \pm 8.9$ \\
$155 \pm 57$
\end{tabular}

\begin{tabular}{c}
\hline $\mathbf{C O N}_{\text {HFD }}(n=11)$ \\
\hline $1.41 \pm 0.38^{\mathrm{a}}$ \\
$5429 \pm 1527^{\mathrm{a}}$ \\
$25.0 \pm 3.2$ \\
$0.34 \pm 0.06$ \\
$622 \pm 68^{\mathrm{a}}$ \\
$13.7 \pm 4.1^{\mathrm{a}}$ \\
$108.9 \pm 26.7^{\mathrm{a}}$ \\
$129 \pm 21$ \\
\hline
\end{tabular}

\begin{tabular}{c}
\hline TEL $_{\text {HFD }}(n=12)$ \\
\hline $0.88 \pm 0.06^{\mathrm{a}, \mathrm{b}}$ \\
$6054 \pm 1213^{\mathrm{a}}$ \\
$20.3 \pm 3.8^{\mathrm{b}}$ \\
$0.15 \pm 0.04^{\mathrm{a}}$ \\
$559 \pm 80^{\mathrm{a}}$ \\
$14.3 \pm 2.2^{\mathrm{a}}$ \\
$123.5 \pm 18.4^{\mathrm{a}}$ \\
$108 \pm 22^{\mathrm{a}}$ \\
\hline
\end{tabular}

$$
\begin{aligned}
\mathrm{FW} & =15.4 P=0.0002 \\
\mathrm{H} & =18.9, P<0.0001 \\
\mathrm{~F} & =4.2, P=0.023 \\
\mathrm{~F} & =11.9, P=0.0001 \\
\mathrm{~F} & =17.1, P<0.0001 \\
\mathrm{~F} & =11.5, P=0.0002 \\
\mathrm{~F} & =25.9, P<0.0001 \\
\mathrm{FW} & =4.9, P=0.015
\end{aligned}
$$

Means \pm s.D.; a $P<0.05$ vs $\mathrm{CON}_{\text {chowi }}{ }^{\mathrm{b} P}<0.05$ vs $\mathrm{CON}_{\text {HFD }}$ following ANOVA (F) and Bonferroni's Multiple Comparison Test or Welsh ANOVA test (indicated by $\mathrm{FW}^{W}$ ) followed by Games-Howell's multiple comparisons test or Kruskal-Wallis test (indicated by $\mathrm{H}$ ) and Dunn's multiple comparisons test.

$$
\begin{aligned}
& \text { https://joe.bioscientifica.com } \\
& \text { https://doi.org/10.1530/JOE-19-0319 } 2020 \text { Society for Endocrinology } \\
& \text { Published by Bioscientifica Ltd. } \\
& \text { Printed in Great Britain }
\end{aligned}
$$




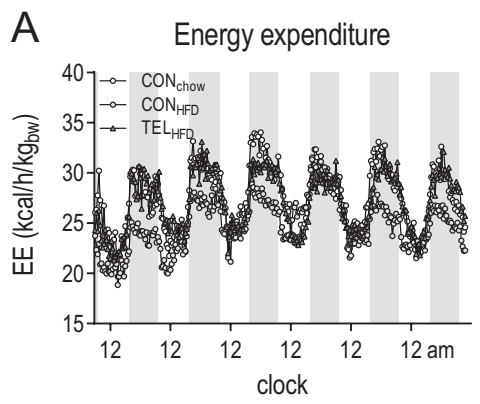

B

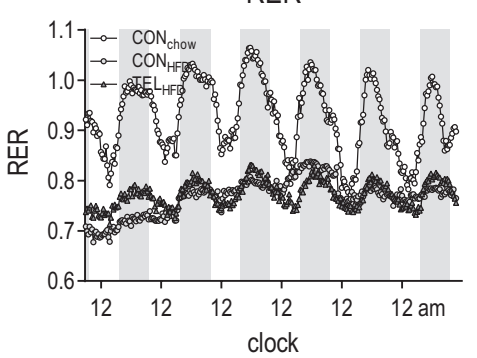

C

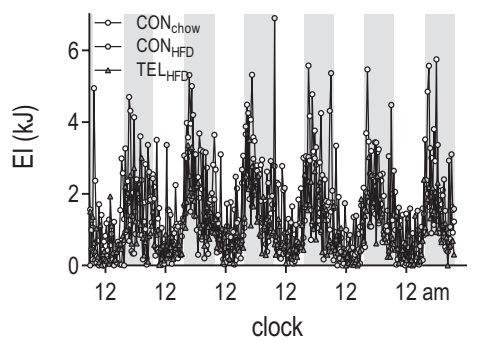

D water intake

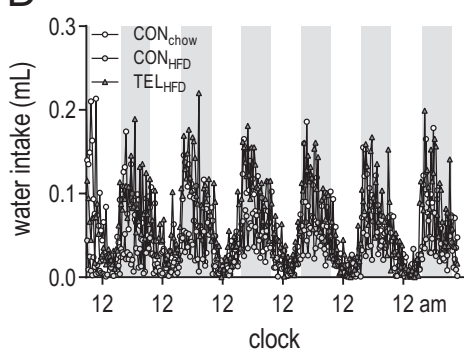

E

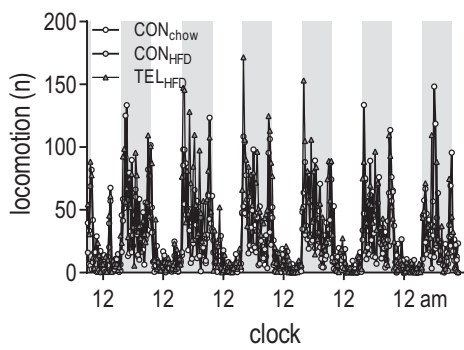

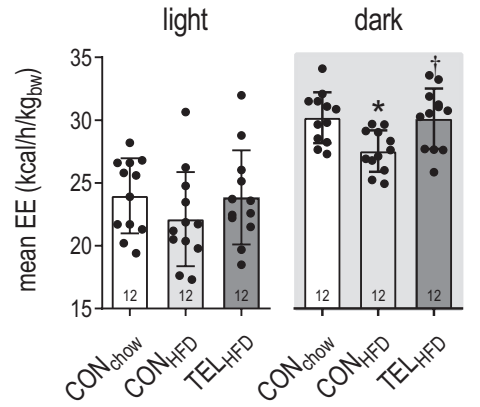
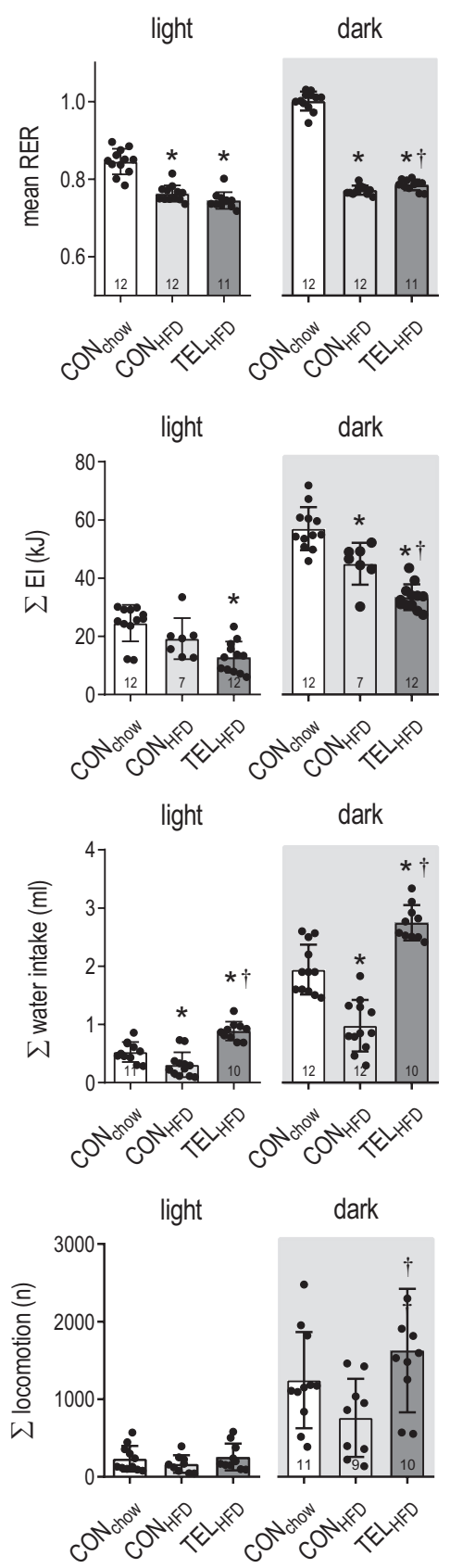

Figure 2

Energy homeostasis of mice upon chow ( $\mathrm{CON}_{\text {chow }}$ ) or HFD feeding plus vehicle treatment ( $\mathrm{CON}_{\text {HFD }}$ ) and HFD feeding plus TEL treatment (TEL $\mathrm{LED}_{\mathrm{HED}}, 8 \mathrm{mg} / \mathrm{kg} / \mathrm{day}$ ). (A) Energy expenditure, light $(F=1.0, P=0.36)$; dark $(F=6.5, P=0.004)$; $(B) R E R$; light $(\mathrm{F}=50.2, P<0.0001)$; $\operatorname{dark}(\mathrm{FW}=640, P<0.0001)$; (C) Energy intake, light ( $F=11.0, P=0.0003)$, dark $(F=41.2, P<0.0001)$; (D) Water intake, light $(F=26.7, P<0.0001)$, dark $(F=53.6$, $P<0.0001)$; (E) Locomotion, light $(F=0.9, P=0.42)$, dark $(F=4.2$, $P=0.026$ ). Means \pm S.D.; Statistical differences between groups were calculated by ANOVA followed by Bonferroni's multiple comparison test or Welsh ANOVA test (indicated by FW) followed by Games-Howell's multiple comparisons test in case of variance inhomogeneity. $* P<0.05$ vs $\mathrm{CON}_{\text {chowi }}{ }^{\dagger} P<0.05$ vs $\mathrm{CON}_{\text {HFD }}$. 
A

baseline glucose

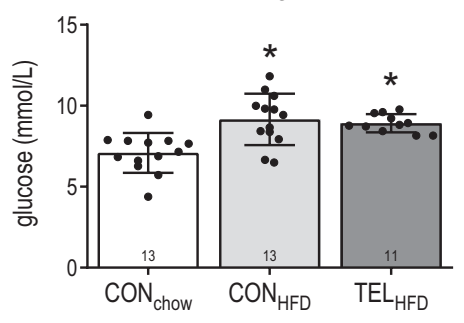

C

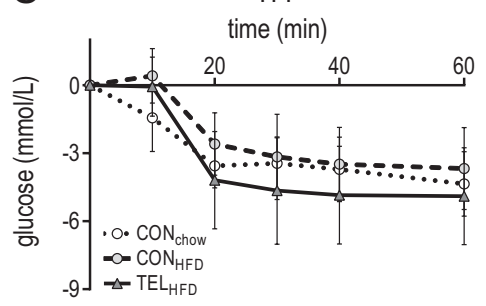

B
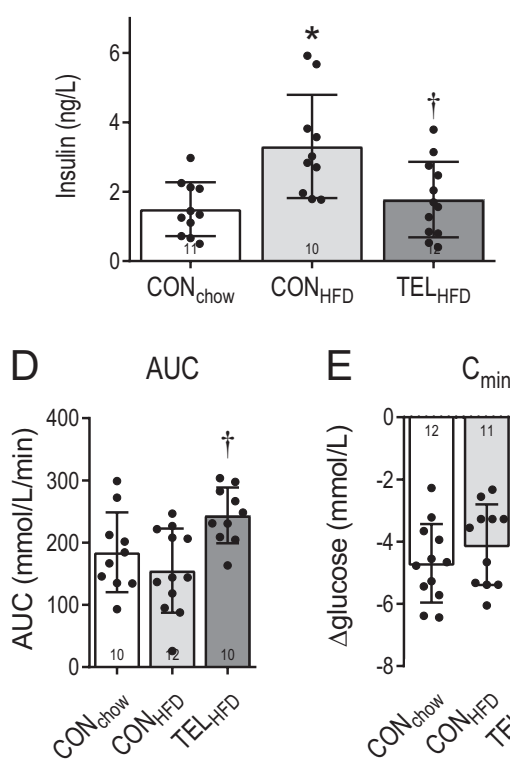

E $\quad \mathrm{C}_{\min }$
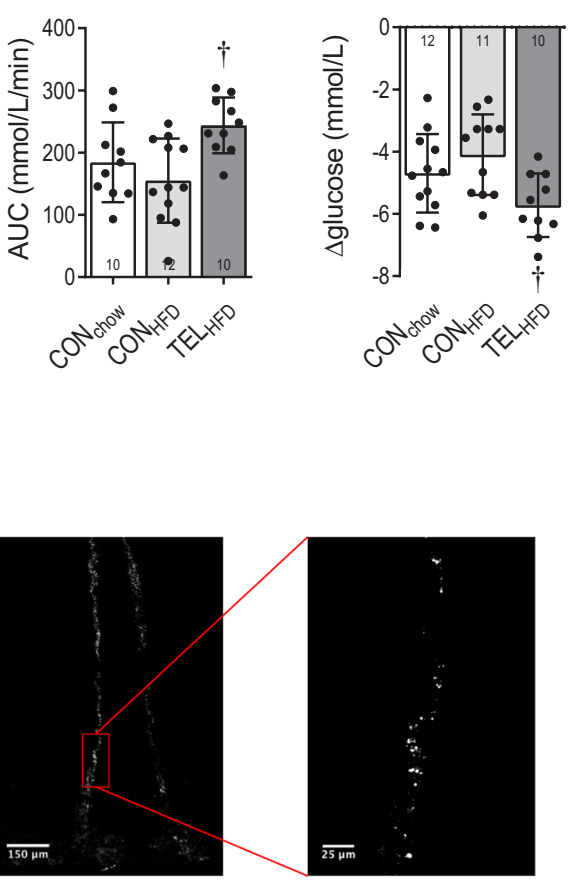

A

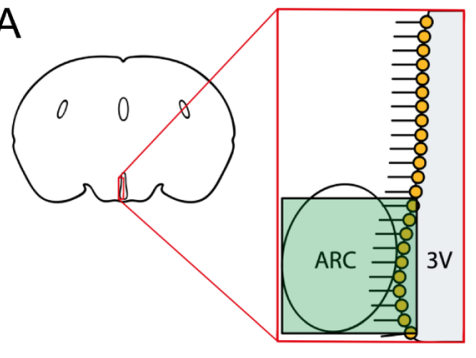

B

LD signal tanycyte layer

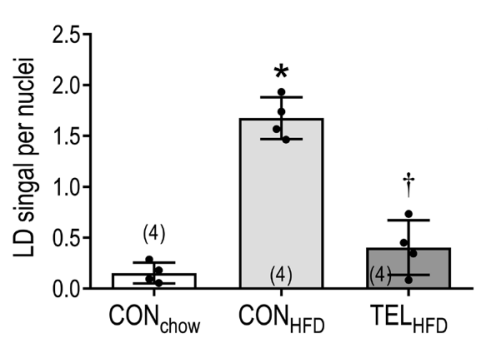

C Triglycerides

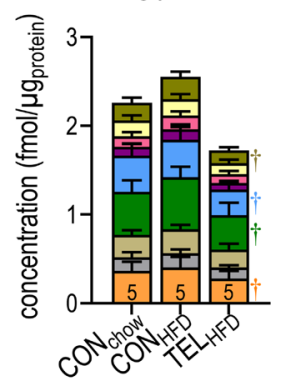

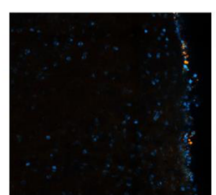
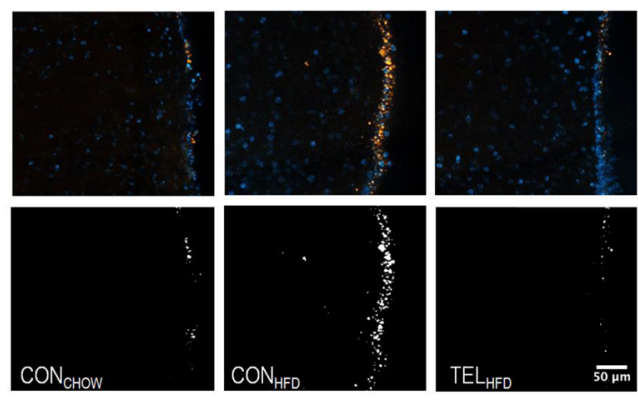

Ceramides

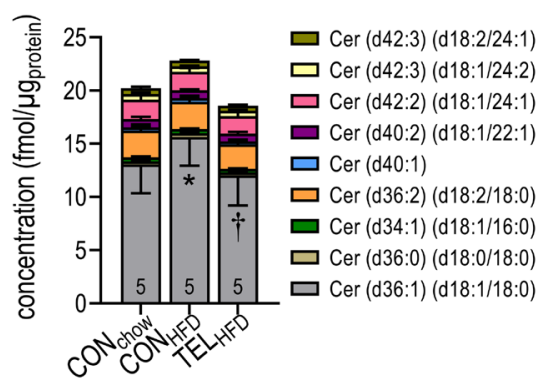

https://joe.bioscientifica.com https://doi.org/10.1530/JOE-19-0319

Figure 3

Glucose control of mice upon chow ( $\left(\mathrm{CON}_{\text {chow }}\right)$ or HFD feeding plus vehicle treatment $\left(\mathrm{CON}_{\mathrm{HFD}}\right)$ and HFD feeding plus TEL treatment (TEL $\mathrm{HFD}_{\text {, }}$ $8 \mathrm{mg} / \mathrm{kg} /$ day). (A) Baseline glucose (ANOVA: $\mathrm{FW}$ 11.9, $P=0.0004$ ); (B) Baseline insulin (ANOVA: F 7.6, $P=0.0021)$; (C) Glucose response upon ITT (2-ANOVA; time: $F$ 128.4, $P<0.0001$; treatment: F 2.0, $P=0.16$; interaction: time: F 3.3, $P=0.0007$ ); (D) AUC of glucose response upon ITT (ANOVA: $\mathrm{F} 6.0, P=0.0065) ;(E) C_{\min }$ of glucose response upon ITT (ANOVA: F 4.8, $P=0.015$ ); Means \pm S.D.; Statistical differences between groups were calculated by ANOVA followed by Bonferroni's multiple comparison test or Welsh ANOVA test (indicated by FW) followed by Games-Howell's multiple comparisons test in case of variance inhomogeneity. ${ }^{*} P<0.05$ vs $\operatorname{CON}_{\text {chow }}{ }^{\dagger} P<0.05$ vs $\mathrm{CON}_{\mathrm{HFD}}$.

\section{Figure 4}

Neutral lipid analysis via fluorescence microscopy and by LC-MS in hypothalamic brain slices of mice upon chow $\left(\mathrm{CON}_{\text {chow }}\right)$ or HFD feeding plus vehicle treatment ( $\left.\mathrm{CON}_{\text {HFD }}\right)$ and HFD feeding plus TEL treatment ( $\mathrm{TEL}_{\mathrm{HFD}}, 8 \mathrm{mg} / \mathrm{kg} /$ day). (A) Illustration of the tanycyte layer at the third ventricle and staining of lipid droplets (LD) by LD540 for blinded quantification. LD signals in the tanycyte layer were quantified by employing a threshold value to eliminate signal noise. (B) Quantification of LD signal ( $n=4$ each group, F 64.0, $P<0.0001$; ANOVA followed by Bonferroni's multiple comparison test) and exemplary micrographs showing LD540 (orange) and DAPI (blue) signals (upper panel) or LD540 only (lower panel). (C) Hypothalamic concentrations of ceramides (lipid: $F=309.9$, $P<0.0001$; treatment: $\mathrm{F}=2.8, P=0.064$; interaction: $\mathrm{F}=2.1, P=0.0133$ ) and triglycerides (two-way-ANOVA upon LC-MS measurement followed by Bonferroni's multiple comparison test, lipid: $\mathrm{F}=41.7, P<0.0001$; treatment: $\mathrm{F}=15.6$, $P<0.0001$; interaction: $\mathrm{F}=0.7, P=0.831$ ). Means \pm S.D.; $* P<0.05$ vs $\mathrm{CON}_{\text {chowi }}{ }^{\dagger} P<0.05$ vs $\mathrm{CON}_{\mathrm{HFD}}$. 
A
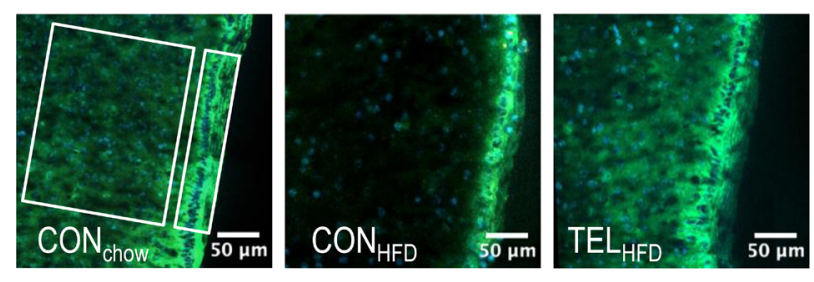

B alkyne LIPID signal (ARC)

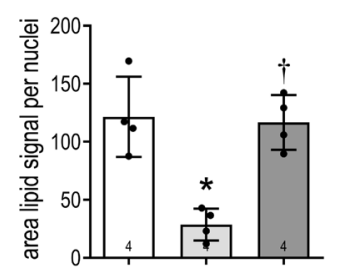

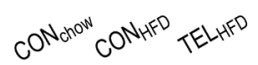

C alkyne oleate metabolism in hypothalamic slices

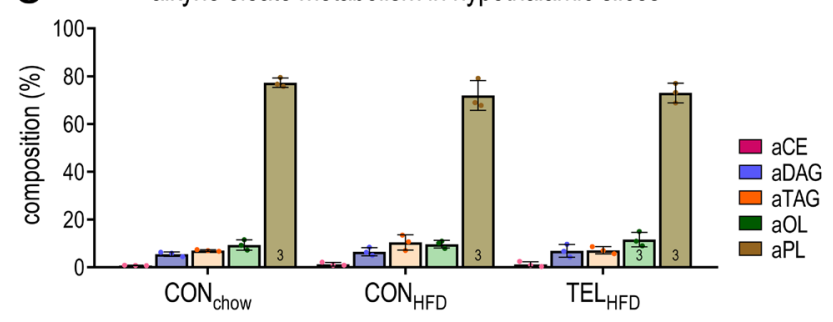

Figure 5

Hypothalamic fatty acid metabolism in slices of mice upon chow $\left(\mathrm{CON}_{\text {chow }}\right)$ or HFD feeding plus vehicle treatment $\left(\mathrm{CON}_{\mathrm{HFD}}\right)$ and HFD feeding plus TEL treatment ( $\mathrm{TEL}_{\mathrm{HFD}}, 8 \mathrm{mg} / \mathrm{kg} /$ day). Analysis of hypothalamic alkyne lipid distribution by fluorescence microscopy. Exemplary micrographs (A) showing alkyne oleate (green) and DAPI (blue) signals and ROIs (left panel) for ARC (large box) and tanycyte layer (small box). (B) Micrographs were quantified and signals in ARC $(F=64.0, P<0.0001)$ or tanycyte layer $(\mathrm{F}=2.5, P=0.136)$ plotted after ANOVA and Bonferroni's multiple comparison test. (C) Analysis of alkyne oleate metabolism in hypothalamic slices of mice upon chow $\left(\mathrm{CON}_{\text {chow }}\right)$ or HFD feeding plus vehicle treatment $\left(\mathrm{CON}_{\mathrm{HFD}}\right)$ and HFD feeding plus TEL treatment ( $\mathrm{TEL}_{\mathrm{HFD}}, 8 \mathrm{mg} / \mathrm{kg} /$ day) by thin-layer chromatography (TLC); aCE, alkyne cholesterolester; aDAG, alkyne diacylglycerol; aTAG, alkyne triacylglycerol; aOL, alkyne oleate; aPL alkyne phospholipids; two-way ANOVA indicated differences in composition of lipids $(F=1233, P<0.0001)$ without differing between the groups.

a natural ligand for trkB (tropomyosin receptor kinase B) that suppresses both appetite and body weight and increases lipolysis in murine models of obesity (Tsao et al. 2008), were interestingly found here to be reduced in $\mathrm{CON}_{\mathrm{HFD}}$ but normalized in $\mathrm{TEL}_{\mathrm{HFD}}$ mice. This finding provides further evidence that the hypothalamic neurocircuits for regulating energy intake are affected by TEL. In contrast, downregulation of hypothalamic expression of $\mathrm{AT}_{1}$ receptors is less involved, as demonstrated here and elsewhere (Muller-Fielitz et al. 2011, Schuchard et al. 2015, Winkler et al. 2016). The pleiotropic potency of ARBs to stimulate PPAR $\gamma$ is likely not related to the observed anorectic effects (Muller-Fielitz et al. 2012, Schuster et al. 2018). As TEL-treated rats preferred chow and the less well-tasting cafeteria diet compared to nontreated controls (Muller-Fielitz et al. 2012, 2015, Schuchard et al. 2015, Winkler et al. 2016), the anti-hedonic behavior may also need to be considered, especially as central RAS regulates reward via the dopaminergic or serotoninergic systems (Voigt et al. 2008, Narayanaswami et al. 2013). We finally investigated whether the potency of ARBs to reduce the drive of the hypothalamic-pituitary-adrenal (HPA) axis contributes to a decrease in food intake. However, we recently demonstrated that stress-induced eating of high-calorie, good-tasting food only plays a minor role or none at all (Gustaityte et al. 2018). As outlined in the introduction, the antiobese effect of ARBs is dependent on intact leptin signaling and leptin penetration across the BBB. Considering the major role of hypothalamic lipid metabolism in the physiological regulation of energy balance (Gonzalez-Garcia et al. 2017), we hypothesized here that improved hypothalamic lipid metabolism represented a potential effect of reconstituting leptin sensitivity due to TEL treatment. As mentioned, tanycytes have been shown to be a conduit for circulating leptin into the hypothalamus (Mullier et al. 2010). Blood-borne leptin is taken up by tanycytes in the median eminence and then released into the mediobasal hypothalamus containing the ARC, a process that is disrupted in mice with diet-induced obesity (Balland et al. 2014). Taken together with further findings showing that HFD feeding triggers neurogenic activity in median eminence tanycytes (Lee et al. 2012), tanycytes might be functionally important for metabolic sensing. Although studies demonstrating an active pathophysiological role of tanycytes in lipid sensing and energy balance control are still lacking, recent evidence suggests that tanycytes play a role in restricting passage of unsaturated fatty acids into the hypothalamus of HFD-fed mice (Hofmann et al. 2017).

Hence, the primary aim of the present study was to investigate the effects of chronic TEL treatment on the hypothalamic lipid profile. To this end, we employed an in vitro system of acute brain-slice cultures incubated with a state-of-the-art alkyne oleate tracer that highly matches natural oleate in structure and biological behavior (Gaebler et al. 2013). Based on this technique we were able to track lipid distribution by fluorescence microscopy and lipid metabolism by TLC analysis. Furthermore, we analyzed cellular lipid droplets, a major site of neutral lipid metabolism and storage (Kuerschner et al. 2008, Walther \& Farese 2012) by fluorescence microscopy. 
A
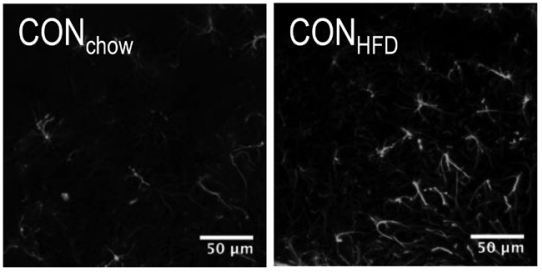

B

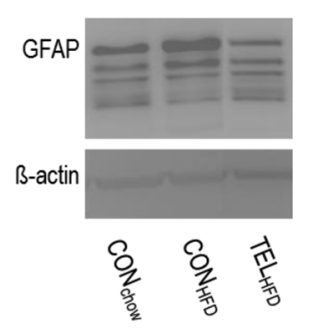

GFAP signal (ARC)
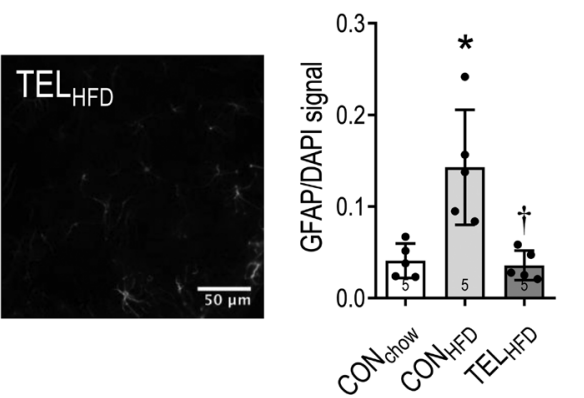

C TNFalpha

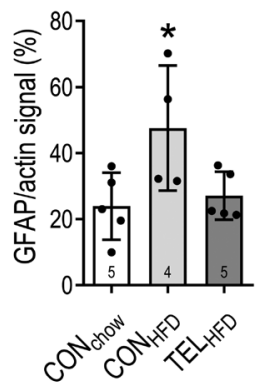

$\mathrm{IL} 1 \alpha$

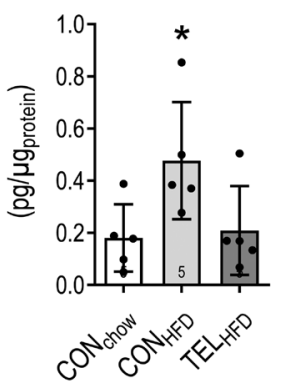

GFAP and bodyweight

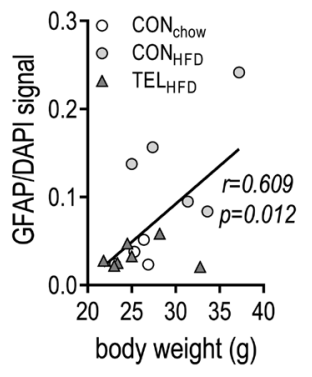

IL13

\section{Figure 6}

Markers of inflammation in hypothalami of mice upon chow $\left(\mathrm{CON}_{\text {chow }}\right)$ or HFD feeding plus vehicle treatment (CON $\left.\mathrm{HFD}\right)$ and $\mathrm{HFD}$ feeding plus TEL treatment ( $\mathrm{TEL}_{\mathrm{HFD}}, 8 \mathrm{mg} / \mathrm{kg} /$ day). (A) Exemplary immunofluorescence micrographs of GFAP expression in the ARC used for signal quantification (FW=6.3, $p=0.027$ ) and in correlation to body weight; (B) Western blot analysis of GFAP expression (FW $=4.6, p=0.036)$; (C) Hypothalamic levels of cytokines (TNF $\alpha$ : $\mathrm{F}=4.2, P=0.042, \mathrm{IL} 1 \alpha: \mathrm{F}=4.1, P=0.07, \mathrm{IL} 13: \mathrm{F}=2.3, P=0.21$ ) determined by immunosorbent assays. Means \pm s.D.; Statistical differences between groups were calculated by ANOVA followed by Bonferroni's Multiple Comparison Test or by Welsh ANOVA test (indicated by FW) followed by Games-Howell's multiple comparisons test in case of variance inhomogeneity. ${ }^{*} P<0.05$ vs $\operatorname{CON}_{\text {chow }}{ }^{\dagger} P<0.05$ vs $\operatorname{CON}_{\mathrm{HFD}}$.

While confirming Hofmann's findings regarding obese $\mathrm{CON}_{\mathrm{HFD}}$ mice (Hofmann et al. 2017), the current study newly demonstrates that TEL treatment not only re-establishes that unsaturated oleic acid labels hypothalamic astrocytes under HFD conditions but also that the LD content of tanycytes that increases as a result of HFD is normalized. Apart from neutral glycerolipids, LDs also contain sterol esters and sphingolipids (Senkal et al. 2017). Such a lipid pattern was confirmed in our LC-MS analyses as levels of TGs and ceramides increased

Table 3 Expression of various genes in hypothalami of mice upon chow ( $\left.\mathrm{CON}_{\text {chow }}\right)$ or $\mathrm{HFD}$ feeding plus vehicle treatment $\left(\mathrm{CON}_{\mathrm{HFD}}\right)$ and HFD feeding plus TEL treatment (TEL $\mathrm{HFD}_{\mathrm{H}} 8 \mathrm{mg} / \mathrm{kg} /$ day).

\begin{tabular}{|c|c|c|c|c|c|c|}
\hline & \multicolumn{3}{|c|}{ Signal (log 2) } & \multicolumn{3}{|c|}{ Fold change ( $P$-value) } \\
\hline & $\mathrm{CON}_{\text {chow }}$ & $\mathrm{CON}_{\mathrm{HFD}}$ & $\mathrm{TEL}_{\mathrm{HFD}}$ & $\mathrm{CON}_{\text {chow }}$ vs CON $\mathrm{CON}_{\mathrm{HFD}}$ & $\mathrm{CON}_{\text {chow }}$ vs TEL $\mathrm{L}_{\text {HFD }}$ & $\mathrm{CON}_{\mathrm{HFD}}$ VS TEL $\mathrm{HFD}_{\mathrm{HF}}$ \\
\hline GFAP & 9.21 & 9.09 & 9.06 & $1.09(0.958)$ & $1.11(0.149)$ & $1.02(0.205)$ \\
\hline Il1alpha & 3.72 & 3.77 & 3.70 & $0.97(0.798)$ & $1.02(0.333)$ & $1.05(0.314)$ \\
\hline 116 & 3.02 & 2.93 & 2.95 & $1.06(0.029)$ & $1.05(0.198)$ & $0.98(0.344)$ \\
\hline II13 & 5.29 & 5.22 & 5.27 & $1.05(0.633)$ & $1.02(0.942)$ & $0.97(0.539)$ \\
\hline $\mathrm{TNF} \alpha$ & 4.71 & 4.68 & 4.78 & $1.02(0.528)$ & $0.95(0.637)$ & $0.93(0.326)$ \\
\hline Interleukin 1 beta & 3.44 & 3.27 & 3.50 & $1.13(0.123)$ & $0.96(0.451)$ & $0.83(0.022)$ \\
\hline Neurotrophin 5 & 4.74 & 4.44 & 4.66 & $1.23(0.000)$ & $1.06(0.286)$ & $0.84(0.003)$ \\
\hline Peroxiredoxin 3 & 8.21 & 8.48 & 8.35 & $0.79(0.000)$ & $0.90(0.030)$ & $1.10(0.071)$ \\
\hline SerpinA3N & 9.17 & 9.64 & 9.12 & $0.62(0.000)$ & $1.03(0.639)$ & $1.43(0.000)$ \\
\hline Cxcl12 & 6.25 & 6.44 & 6.42 & $0.86(0.001)$ & $0.88(0.025)$ & $1.01(0.615)$ \\
\hline Follistatin-like 1 & 7.28 & 7.58 & 7.31 & $0.77(0.001)$ & $0.98(0.943)$ & $1.21(0.002)$ \\
\hline $\begin{array}{l}\text { Cytochrome c oxidase subunit } \\
\text { 5B (mitochondrial) }\end{array}$ & 10.88 & 10.73 & 10.69 & $1.11(0.002)$ & $1.14(0.000)$ & $1.03(0.428)$ \\
\hline \multicolumn{7}{|l|}{$n=20$ each group. } \\
\hline $\begin{array}{l}\text { https://joe.bioscientifica.com } \\
\text { https://doi.org/10.1530/JOE-19-0319 }\end{array}$ & (c) 2020 & $\begin{array}{l}\text { Endocrin } \\
\text { scientific } \\
\text { in Great B }\end{array}$ & & & & \\
\hline
\end{tabular}


in the hypothalami of $\mathrm{CON}_{\mathrm{HFD}}$ mice but were normalized by TEL. It is worthy of note that LDs appear to play a crucial role in mitigating ER stress caused by excess of saturated fatty acids on HFD (Welte \& Gould 2017). Recent evidence indicates that overnutrition causes ER stress by increasing ceramide levels in the hypothalamus, inducing insulin and leptin resistance (Contreras et al. 2014). Conversely, inhibiting central ceramide synthesis restores insulin signaling in the hypothalamus of obese Zucker rats (Campana et al. 2018). Accordingly, our observed boost in hypothalamic TGs and ceramides in $\mathrm{CON}_{\mathrm{HFD}}$ mice and their normalization upon TEL treatment may indicate an influence of the drug on ER stress. Thus, this pathway must additionally be considered for maintaining insulin sensitivity under ARB treatment, although other pleiotropic effects such as PPAR $\gamma$-dependent or HPAdependent mechanisms are well established (Kintscher et al. 2008, Miesel et al. 2012).

As the accumulation of unfolded or misfolded proteins due to ER stress can initiate inflammation (Zhang \& Kaufman 2008), hypothalamic lipotoxicity and inflammation are inextricably linked with each other. Hypothalamic inflammation was shown to induce central leptin resistance associated with the development of obesity (De Souza et al. 2005). Remarkably, inflammation can be detected in the hypothalamus after only 1 day of HFD feeding and, therefore, before body weight has been gained, suggesting a cause in the pathophysiology of obesity (Thaler et al. 2012). Moreover, reduced leptin transition across the BBB of obese mice (serving as an indicator for leptin resistance) was also attributed to a reactive gliosis due to low-grade inflammation as described in the hypothalamus of obese rodents and humans (Thaler et al. 2012). Accordingly, HFD feeding was associated with an impairment in BBB structure due to astrocytic gliosis such that feeding behavior regulating POMC (pro-opiomelanocortin) and NPY (neuropeptide Y) neurons became less accessible to blood-borne metabolic signals (Horvath et al. 2010).

Considering all these findings, we further investigated the anti-inflammatory potential of TEL during HFD feeding. In accordance with the established knowledge that upregulation of GFAP serves as a common marker of astrogliosis (Filous \& Silver 2016, Li et al. 2019), we have indeed confirmed previous findings (Lee et al. 2018) that hypothalamic inflammation and abnormal glucose metabolism develop in cases of overnutritioninduced obesity. Normalized GFAP protein levels and immunoreactivity in $\mathrm{TEL}_{\mathrm{HFD}}$ mice may consequently indicate that astrogliosis can be prevented by blocking $\mathrm{AT}_{1}$ receptors despite HFD feeding. This finding is furthermore in line with the reduction of TNF $\alpha$ and IL1 $\alpha$ levels in these animals. Both TNF $\alpha$ and IL1 $\alpha$ were observed to activate NF- $\mathrm{kB}$ (nuclear factor kappa B) in cultured hypothalamic neurons (Jang et al. 2010), which can induce SOCS3 (suppressor of cytokine signaling 3) and PTP1B (protein tyrosine phosphatase 1B) expression and result in leptin resistance (de Git \& Adan 2015). However, we did not detect an influence of either HFD feeding or TEL treatment on gene expression of GFAP, IL $1 \alpha$, or TNF $\alpha$. This may be attributable to post-transcriptional and translational protein degradation regulation. Hypothalamic inflammation as a result of obesity and its prevention by TEL is once more confirmed by our Affimetrix arrays as expression levels of SerpinA3N, follistatin-like 1, and Cxcl12, which all have been implicated in nutritionally mediated hypothalamic inflammation, were increased in $\mathrm{CON}_{\mathrm{HFD}}$ and again normalized in $\mathrm{TEL}_{\mathrm{HFD}}$. With respect to tissue specificity, the anti-inflammatory effect of TEL is likely not a widespread feature. This notion is supported by the fact that TEL affects the levels of the pro- and antiinflammatory cyto- and adipokines such as resistin, IL-4, and IL-5 predominately in CNS but not in plasma.

As recently identified, a lack of body weight gain despite HFD upon TEL treatment is partly mediated by an off-target mechanism via an ACE2/angiotensin-(1-7)/ Mas-dependent pathway (Schuchard et al. 2015). Indeed, several studies support an anti-inflammatory effect of the ACE2/Ang-(1-7)/Mas axis (Simões e Silva et al. 2013), as i.c.v infusion of Ang-(1-7) was found to reduce NF-кB activity in brain tissue after cerebral ischemia, which was associated with decreased expression levels of TNF- $\alpha$ and IL-1 $\beta$ (Jiang et al. 2012). However, there is a lack of data concerning an Ang-(1-7) effect on hypothalamic lipid metabolism, although peripheral lipids are decreased by Ang-(1-7) (Moreira et al. 2017). In addition, several in vitro and in vivo studies have determined that TEL itself shows anti-(neuro) inflammatory potential (Saravanan et al. 2015, Xu et al. 2015, Li et al. 2016). Interestingly, a TEL-associated reduction in adipogenesis and body weight gain was blocked after PPAR- $\delta$ gene knockout (He et al. 2010). Considering that PPAR- $\delta$ is involved in controlling energy homeostasis by stimulating genes for fatty acid catabolism and is thought to protect against the neuronal effects of saturated fatty acids (Poon et al. 2015), a further potential mechanism of TEL's anti-obese effect becomes apparent.

In summary, our data show that TEL treatment normalizes hypothalamic ceramide levels, TG levels, and alkyne oleate distribution despite HFD. The abolished 
accumulation of neutral lipids and lipotoxicity are further accompanied by an anti-inflammatory effect in the murine hypothalamus. These findings further add to the knowledge of the weight-regulating effects of TEL in the body (Supplementary Fig. 8).

\section{Supplementary materials}

This is linked to the online version of the paper at https://doi.org/10.1530/ JOE-19-0319.

\section{Declaration of interest}

The authors declare that there is no conflict of interest that could be perceived as prejudicing the impartiality of the research reported.

\section{Funding}

This publication was supported by a grant (81X2700119) of the DZHK (German Centre for Cardiovascular Research) and by a grant of the German Research Foundation to the Graduiertenkolleg 1957 'AdipocyteBrain Crosstalk', University of Lübeck. Telmisartan was a kind gift from Böhringer Ingelheim, Germany. Parts of the work presented in the article were presented at the 3nd Pharm-Tox Summit in Göttingen, Germany, 2018 (Naunyn-Schmiedebergs Archives of Pharmacology, 391 (Suppl. 1, S25 [P03])).

\section{Author contribution statement}

E R, L K, L N, F S, I S, A F, K S, N H, A O, and W R performed the research; $E R, L K$, and W R designed the research study; E R, A O and W R analyzed the data; and W R and E R wrote the paper.

\section{Acknowledgments}

The authors thank Prof Dr Marcus Altfeld and Urte Matschl from the Heinrich Pette Institute, Hamburg, for the measurements with the Luminex system. The authors gratefully acknowledge Sherryl Sundell for improving the English style.

\section{References}

Balland E, Dam J, Langlet F, Caron E, Steculorum S, Messina A, Rasika S, Falluel-Morel A, Anouar Y, Dehouck B, et al. 2014 Hypothalamic tanycytes are an ERK-gated conduit for leptin into the brain. Cell Metabolism 19 293-301. (https://doi.org/10.1016/j.cmet.2013.12.015)

Banks WA, Farr SA, Salameh TS, Niehoff ML, Rhea EM, Morley JE, Hanson AJ, Hansen KM \& Craft S 2018 Triglycerides cross the bloodbrain barrier and induce central leptin and insulin receptor resistance. International Journal of Obesity 42 391-397. (https://doi.org/10.1038/ ijo.2017.231)

Barahona MJ, Llanos P, Recabal A, Escobar-Acuna K, Elizondo-Vega R, Salgado M, Ordenes P, Uribe E, Sepulveda FJ, Araneda RC, et al. 2018 Glial hypothalamic inhibition of GLUT2 expression alters satiety, impacting eating behavior. Glia 66 592-605. (https://doi.org/10.1002/ glia.23267)

Campana M, Bellini L, Rouch C, Rachdi L, Coant N, Butin N, Bandet CL, Philippe E, Meneyrol K, Kassis N, et al. 2018 Inhibition of central de novo ceramide synthesis restores insulin signaling in hypothalamus and enhances beta-cell function of obese Zucker rats. Molecular Metabolism 8 23-36. (https://doi.org/10.1016/j.molmet.2017.10.013)

Cheng L, Yu Y, Szabo A, Wu Y, Wang H, Camer D \& Huang XF 2015 Palmitic acid induces central leptin resistance and impairs hepatic glucose and lipid metabolism in male mice. Journal of Nutritional Biochemistry $\mathbf{2 6}$ 541-548. (https://doi.org/10.1016/j.jnutbio.2014.12.011)

Contreras C, Gonzalez-Garcia I, Martinez-Sanchez N, Seoane-Collazo P, Jacas J, Morgan DA, Serra D, Gallego R, Gonzalez F, Casals N, et al. 2014 Central ceramide-induced hypothalamic lipotoxicity and ER stress regulate energy balance. Cell Reports 9 366-377. (https://doi.org/ 10.1016/j.celrep.2014.08.057)

Cortes-Campos C, Elizondo R, Llanos P, Uranga RM, Nualart F \& Garcia MA 2011 MCT expression and lactate influx/efflux in tanycytes involved in glia-neuron metabolic interaction. PLOS ONE 6 e16411. (https://doi.org/10.1371/journal.pone.0016411)

Cortes-Campos C, Elizondo R, Carril C, Martinez F, Boric K, Nualart F \& Garcia-Robles MA 2013 MCT2 expression and lactate influx in anorexigenic and orexigenic neurons of the arcuate nucleus. PLoS ONE 8 e62532. (https://doi.org/10.1371/journal.pone.0062532)

Dapper C, Schuster F, Stölting I, Vogt F, Castro E Souza LA, Alenina N, Bader M \& Raasch W 2019 The antiobese effect of AT1 receptor blockade is augmented in mice lacking Mas. Naunyn-Schmiedeberg's Archives of Pharmacology 392 865-877. (https://doi.org/10.1007/ s00210-019-01643-0)

De Git KC \& Adan RA 2015 Leptin resistance in diet-induced obesity: the role of hypothalamic inflammation. Obesity Reviews 16 207-224. (https://doi.org/10.1111/obr.12243)

De Souza CT, Araujo EP, Bordin S, Ashimine R, Zollner RL, Boschero AC, Saad MJ \& Velloso LA 2005 Consumption of a fat-rich diet activates a proinflammatory response and induces insulin resistance in the hypothalamus. Endocrinology 146 4192-4199. (https://doi.org/ 10.1210/en.2004-1520)

Elizondo-Vega R, Cortes-Campos C, Barahona MJ, Carril C, Ordenes P, Salgado M, Oyarce K \& Garcia-Robles ML 2016 Inhibition of hypothalamic MCT1 expression increases food intake and alters orexigenic and anorexigenic neuropeptide expression. Scientific Reports 6 33606. (https://doi.org/10.1038/srep33606)

Filous AR \& Silver J 2016 Targeting astrocytes in CNS injury and disease: a translational research approach. Progress in Neurobiology 144 173-187. (https://doi.org/10.1016/j.pneurobio.2016.03.009)

Frayling C, Britton R \& Dale N 2011 ATP-mediated glucosensing by hypothalamic tanycytes. Journal of Physiology 589 2275-2286. (https://doi.org/10.1113/jphysiol.2010.202051)

Friedman J 2016 The long road to leptin. Journal of Clinical Investigation 126 4727-4734. (https://doi.org/10.1172/JCI91578)

Gaebler A, Milan R, Straub L, Hoelper D, Kuerschner L \& Thiele C 2013 Alkyne lipids as substrates for click chemistry-based in vitro enzymatic assays. Journal of Lipid Research 54 2282-2290. (https://doi. org/10.1194/jlr.D038653)

Gonzalez-Garcia I, Ferno J, Dieguez C, Nogueiras R \& Lopez M 2017 Hypothalamic lipids: key regulators of whole body energy balance. Neuroendocrinology 104 398-411. (https://doi.org/10.1159/ 000448432)

Gustaityte V, Winkler M, Stölting I \& Raasch W 2018 Influence of AT1 blockers on obesity and stress induced eating of cafeteria diet. Journal of Endocrinology 240 65-79. (https://doi.org/10.1530/JOE-18-0477)

He H, Yang D, Ma L, Luo Z, Ma S, Feng X, Cao T, Yan Z, Liu D, Tepel M, et al. 2010 Telmisartan prevents weight gain and obesity through activation of peroxisome proliferator-activated receptor-deltadependent pathways. Hypertension 55 869-879. (https://doi.org/ 10.1161/HYPERTENSIONAHA.109.143958) https://joe.bioscientifica.com https://doi.org/10.1530/JOE-19-0319 (c) 2020 Society for Endocrinology Published by Bioscientifica Ltd.
Printed in Great Britain 
Hofmann K, Thiele C, Schott HF, Gaebler A, Schoene M, Kiver Y, Friedrichs S, Lutjohann D \& Kuerschner L 2014 A novel alkyne cholesterol to trace cellular cholesterol metabolism and localization. Journal of Lipid Research 55 583-591. (https://doi.org/10.1194/jlr. D044727)

Hofmann K, Lamberz C, Piotrowitz K, Offermann N, But D, Scheller A, Al-Amoudi A \& Kuerschner L 2017 Tanycytes and a differential fatty acid metabolism in the hypothalamus. Glia 65 231-249. (https:// doi.org/10.1002/glia.23088)

Horvath TL, Sarman B, Garcia-Caceres C, Enriori PJ, Sotonyi P, Shanabrough M, Borok E, Argente J, Chowen JA, Perez-Tilve D, et al. 2010 Synaptic input organization of the melanocortin system predicts diet-induced hypothalamic reactive gliosis and obesity. PNAS 107 14875-14880. (https://doi.org/10.1073/pnas.1004282107)

Jang PG, Namkoong C, Kang GM, Hur MW, Kim SW, Kim GH, Kang Y, Jeon MJ, Kim EH, Lee MS, et al. 2010 NF-kappaB activation in hypothalamic pro-opiomelanocortin neurons is essential in illnessand leptin-induced anorexia. Journal of Biological Chemistry $\mathbf{2 8 5}$ 9706-9715. (https://doi.org/10.1074/jbc.M109.070706)

Jastroch M, Morin S, Tschop MH \& Yi CX 2014 The hypothalamic neural-glial network and the metabolic syndrome. Best Practice and Research. Clinical Endocrinology and Metabolism 28 661-671. (https:// doi.org/10.1016/j.beem.2014.02.002)

Jiang T, Gao L, Guo J, Lu J, Wang Y \& Zhang Y 2012 Suppressing inflammation by inhibiting the NF-kappaB pathway contributes to the neuroprotective effect of angiotensin-(1-7) in rats with permanent cerebral ischaemia. British Journal of Pharmacology 167 1520-1532. (https://doi.org/10.1111/j.1476-5381.2012.02105.x)

Kintscher U, Bramlage P, Paar WD, Thoenes M \& Unger T 2007 Irbesartan for the treatment of hypertension in patients with the metabolic syndrome: a sub analysis of the treat to target post authorization survey. Prospective observational, two armed study in 14,200 patients. Cardiovascular Diabetology 6 12. (https://doi. org/10.1186/1475-2840-6-12)

Kintscher U, Foryst-Ludwig A \& Unger T 2008 Inhibiting angiotensin type 1 receptors as a target for diabetes. Expert Opinion on Therapeutic Targets 12 1257-1263. (https://doi.org/10.1517/14728222.12.10.1257)

Kolb HC, Finn MG \& Sharpless KB 2001 Click chemistry: diverse chemical function from a few good reactions. Angewandte Chemie 40 2004-2021. (https://doi.org/10.1002/1521-3773(20010601)40:11<2004::aidanie2004>3.3.co;2-x)

Konner AC \& Bruning JC 2012 Selective insulin and leptin resistance in metabolic disorders. Cell Metabolism 16 144-152. (https://doi.org/ 10.1016/j.cmet.2012.07.004)

Kuerschner L, Moessinger C \& Thiele C 2008 Imaging of lipid biosynthesis: how a neutral lipid enters lipid droplets. Traffic 9 338-352. (https://doi.org/10.1111/j.1600-0854.2007.00689.x)

Le Foll C, Dunn-Meynell AA, Miziorko HM \& Levin BE 2014 Regulation of hypothalamic neuronal sensing and food intake by ketone bodies and fatty acids. Diabetes 63 1259-1269. (https://doi.org/10.2337/ db13-1090)

Lee DA, Bedont JL, Pak T, Wang H, Song J, Miranda-Angulo A, Takiar V, Charubhumi V, Balordi F, Takebayashi H, et al. 2012 Tanycytes of the hypothalamic median eminence form a diet-responsive neurogenic niche. Nature Neuroscience 15 700-702. (https://doi.org/10.1038/ nn.3079)

Lee CH, Kim HJ, Lee YS, Kang GM, Lim HS, Lee SH, Song DK, Kwon O, Hwang I, Son M, et al. 2018 Hypothalamic macrophage inducible nitric oxide synthase mediates obesity-associated hypothalamic inflammation. Cell Reports 25 934.e5-946.e5. (https://doi.org/ 10.1016/j.celrep.2018.09.070)

Li HB, Li X, Huo CJ, Su Q, Guo J, Yuan ZY, Zhu GQ, Shi XL, Liu JJ \& Kang YM 2016 TLR4/MyD88/NF-кB signaling and PPAR- $\gamma$ within the paraventricular nucleus are involved in the effects of telmisartan in hypertension. Toxicology and Applied Pharmacology 305 93-102. (https://doi.org/10.1016/j.taap.2016.06.014)
Li T, Chen X, Zhang C, Zhang Y \& Yao W 2019 An update on reactive astrocytes in chronic pain. Journal of Neuroinflammation 16140. (https://doi.org/10.1186/s12974-019-1524-2)

Miesel A, Muller-Fielitz H, Johren O, Vogt FM \& Raasch W 2012 Double blockade of angiotensin II (AT(1))-receptors and ACE does not improve weight gain and glucose homeostasis better than singledrug treatments in obese rats. British Journal of Pharmacology 165 2721-2735. (https://doi.org/10.1111/j.1476-5381.2011.01726.x)

Moreira CCL, Lourenco FC, Mario ÉG, Santos RAS, Botion LM \& Chaves VE 2017 Long-term effects of angiotensin-(1-7) on lipid metabolism in the adipose tissue and liver. Peptides 92 16-22. (https://doi.org/10.1016/j.peptides.2017.04.004)

Muller-Fielitz H, Markert A, Wittmershaus C, Pahlke F, Johren O \& Raasch W 2011 Weight loss and hypophagia after high-dose AT1blockade is only observed after high dosing and depends on regular leptin signalling but not blood pressure. Naunyn-Schmiedeberg's Archives of Pharmacology 383 373-384. (https://doi.org/10.1007/ s00210-011-0602-5)

Muller-Fielitz H, Landolt J, Heidbreder M, Werth S, Vogt FM, Johren O \& Raasch W 2012 Improved insulin sensitivity after long-term treatment with AT1 blockers is not associated with PPARgamma target gene regulation. Endocrinology 153 1103-1115. (https://doi.org/10.1210/ en.2011-0183)

Muller-Fielitz H, Hubel N, Mildner M, Vogt FM, Barkhausen J \& Raasch W 2014 Chronic blockade of angiotensin AT(1) receptors improves cardinal symptoms of metabolic syndrome in diet-induced obesity in rats. British Journal of Pharmacology 171 746-760. (https://doi. org/10.1111/bph.12510)

Muller-Fielitz H, Lau M, Geissler C, Werner L, Winkler M \& Raasch W 2015 Preventing leptin resistance by blocking angiotensin II AT1 receptors in diet-induced obese rats. British Journal of Pharmacology 172 857-868. (https://doi.org/10.1111/bph.12949)

Mullier A, Bouret SG, Prevot V \& Dehouck B 2010 Differential distribution of tight junction proteins suggests a role for tanycytes in blood-hypothalamus barrier regulation in the adult mouse brain. Journal of Comparative Neurology 518 943-962. (https://doi. org/10.1002/cne.22273)

Narayanaswami V, Somkuwar SS, Horton DB, Cassis LA \& Dwoskin LP 2013 Angiotensin AT1 and AT2 receptor antagonists modulate nicotine-evoked $[(3) \mathrm{H}]$ dopamine and $[(3) \mathrm{H}]$ norepinephrine release. Biochemistry and Pharmacology 86 656-665. (https://doi.org/10.1016/ j.bcp.2013.06.025)

Obici S, Feng Z, Morgan K, Stein D, Karkanias G \& Rossetti L 2002 Central administration of oleic acid inhibits glucose production and food intake. Diabetes 51 271-275. (https://doi.org/10.2337/diabetes. 51.2.271)

Othman A, Rutti MF, Ernst D, Saely CH, Rein P, Drexel H, PorrettaSerapiglia C, Lauria G, Bianchi R, Von Eckardstein A, et al. 2012 Plasma deoxysphingolipids: a novel class of biomarkers for the metabolic syndrome? Diabetologia 55 421-431. (https://doi.org/10.1007/s00125011-2384-1)

Poon K, Alam M, Karatayev O, Barson JR \& Leibowitz SF 2015 Regulation of the orexigenic neuropeptide, enkephalin, by PPARdelta and fatty acids in neurons of the hypothalamus and forebrain. Journal of Neurochemistry 135 918-931. (https://doi. org/10.1111/jnc.13298)

Posey KA, Clegg DJ, Printz RL, Byun J, Morton GJ, VivekanandanGiri A, Pennathur S, Baskin DG, Heinecke JW, Woods SC, et al. 2009 Hypothalamic proinflammatory lipid accumulation, inflammation, and insulin resistance in rats fed a high-fat diet. American Journal of Physiology: Endocrinology and Metabolism 296 E1003-E1012. (https://doi.org/10.1152/ajpendo.90377.2008)

Saravanan PB, Shanmuganathan MV \& Ramanathan M 2015 Telmisartan attenuated LPS-induced neuroinflammation in human IMR-32 neuronal cell line via SARM in AT1R independent mechanism. Life Sciences 130 88-96. (https://doi.org/10.1016/j.lfs.2015.03.005) https://joe.bioscientifica.com

https://doi.org/10.1530/JOE-19-0319 (c) 2020 Society for Endocrinology Published by Bioscientifica Ltd. Printed in Great Britain 
Schindelin J, Arganda-Carreras I, Frise E, Kaynig V, Longair M, Pietzsch T, Preibisch S, Rueden C, Saalfeld S, Schmid B, et al. 2012 Fiji: an open-source platform for biological-image analysis. Nature Methods 9 676-682. (https://doi.org/10.1038/nmeth.2019)

Schuchard J, Winkler M, Stolting I, Schuster F, Vogt FM, Barkhausen J, Thorns C, Santos RA, Bader M \& Raasch W 2015 Lack of weight gain after angiotensin AT1 receptor blockade in diet-induced obesity is partly mediated by an angiotensin-(1-7)/Mas-dependent pathway. British Journal of Pharmacology 172 3764-3778. (https://doi. org/10.1111/bph.13172)

Schuster F, Huber G, Stolting I, Wing EE, Saar K, Hubner N, Banks WA \& Raasch W 2018 Telmisartan prevents diet-induced obesity and preserves leptin transport across the blood-brain barrier in high-fat diet-fed mice. Pflugers Archiv 470 1673-1689. (https://doi.org/10.1007/ s00424-018-2178-0)

Senkal CE, Salama MF, Snider AJ, Allopenna JJ, Rana NA, Koller A, Hannun YA \& Obeid LM 2017 Ceramide is metabolized to acylceramide and stored in lipid droplets. Cell Metabolism $\mathbf{2 5}$ 686-697. (https://doi.org/10.1016/j.cmet.2017.02.010)

Simões e Silva AC, Silveira KD, Ferreira AJ \& Teixeira MM 2013 ACE2, angiotensin-(1-7) and Mas receptor axis in inflammation and fibrosis. British Journal of Pharmacology 169 477-492. (https://doi.org/10.1111/ bph.12159)

Spandl J, White DJ, Peychl J \& Thiele C 2009 Live cell multicolor imaging of lipid droplets with a new dye, LD540. Traffic 10 1579-1584. (https://doi.org/10.1111/j.1600-0854.2009.00980.x)

Thaler JP, Yi CX, Schur EA, Guyenet SJ, Hwang BH, Dietrich MO, Zhao X, Sarruf DA, Izgur V, Maravilla KR, et al. 2012 Obesity is associated with hypothalamic injury in rodents and humans. Journal of Clinical Investigation 122 153-162. (https://doi.org/10.1172/JCI59660)

Thiele C, Papan C, Hoelper D, Kusserow K, Gaebler A, Schoene M, Piotrowitz K, Lohmann D, Spandl J, Stevanovic A, et al. 2012 Tracing fatty acid metabolism by click chemistry. ACS Chemical Biology $\mathbf{7}$ 2004-2011. (https://doi.org/10.1021/cb300414v)

Tsao D, Thomsen HK, Chou J, Stratton J, Hagen M, Loo C, Garcia C, Sloane DL, Rosenthal A \& Lin JC 2008 TrkB agonists ameliorate obesity and associated metabolic conditions in mice. Endocrinology 149 1038-1048. (https://doi.org/10.1210/en.2007-1166)

Valdearcos M, Xu AW \& Koliwad SK 2015 Hypothalamic inflammation in the control of metabolic function. Annual Review of Physiology $\mathbf{7 7}$ 131-160. (https://doi.org/10.1146/annurev-physiol-021014-071656)

Voigt JP, Raasch W, Hortnagl H, Bader M, Fink H \& Johren O 2008 Changes in the brain serotonin satiety system in transgenic rats lacking brain angiotensinogen. Journal of Neuroendocrinology $\mathbf{2 0}$ 182-187. (https://doi.org/10.1111/j.1365-2826.2007.01631.x)

Walther TC \& Farese RV 2012 Lipid droplets and cellular lipid metabolism. Annual Review of Biochemistry 81 687-714. (https://doi. org/10.1146/annurev-biochem-061009-102430)

Welte MA \& Gould AP 2017 Lipid droplet functions beyond energy storage. Biochimica et Biophysica Acta: Molecular and Cell Biology of Lipids 1862 1260-1272. (https://doi.org/10.1016/j.bbalip.2017.07.006)

Winkler M, Schuchard J, Stolting I, Vogt FM, Barkhausen J, Thorns C, Bader M \& Raasch W 2016 The brain renin-angiotensin system plays a crucial role in regulating body weight in diet-induced obesity in rats. British Journal of Pharmacology 173 1602-1617. (https://doi. org/10.1111/bph.13461)

Xu Y, Xu Y, Wang Y, Wang Y, He L, Jiang Z, Huang Z, Liao H, Li J, Saavedra JM, et al. 2015 Telmisartan prevention of LPS-induced microglia activation involves M2 microglia polarization via CaMKK $\beta$ dependent AMPK activation. Brain, Behavior, and Immunity 50 298-313. (https://doi.org/10.1016/j.bbi.2015.07.015)

Zhang K \& Kaufman RJ 2008 From endoplasmic-reticulum stress to the inflammatory response. Nature $\mathbf{4 5 4} 455-462$. (https://doi.org/ 10.1038/nature07203)

Received in final form 10 September 2019

Accepted 4 October 2019

Accepted Manuscript published online 4 October 2019
(C) 2020 Society for Endocrinology Published by Bioscientifica Ltd. 